ARTICLE

https://doi.org/10.1038/s41467-022-28380-y

\title{
Few-layer bismuth selenide cathode for low-temperature quasi-solid-state aqueous zinc metal batteries
}

Yuwei Zhao ${ }^{1}$, Yue Lu ${ }^{2}$, Huiping $\mathrm{Li}^{3}$, Yongbin Zhu ${ }^{4}$, You Meng $\mathbb{D}^{1}{ }^{1}, \mathrm{Na} \mathrm{Li}^{1}$, Donghong Wang ${ }^{1}$ Feng Jiang ${ }^{4}$, Funian Mo ${ }^{1}$, Changbai Long ${ }^{5}$, Ying Guo ${ }^{1}$, Xinliang Li ${ }^{1}$, Zhaodong Huang ${ }^{1}$, Qing Li ${ }^{1}$, Johnny C. Ho (1) ${ }^{1}$, Jun Fan (1) ${ }^{1}$,

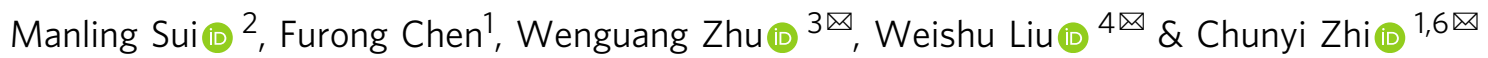

The performances of rechargeable batteries are strongly affected by the operating environmental temperature. In particular, low temperatures (e.g., $\leq 0^{\circ} \mathrm{C}$ ) are detrimental to efficient cell cycling. To circumvent this issue, we propose a few-layer $\mathrm{Bi}_{2} \mathrm{Se}_{3}$ (a topological insulator) as cathode material for $\mathrm{Zn}$ metal batteries. When the few-layer $\mathrm{Bi}_{2} \mathrm{Se}_{3}$ is used in combination with an anti-freeze hydrogel electrolyte, the capacity delivered by the cell at $-20^{\circ} \mathrm{C}$ and $1 \mathrm{Ag}^{-1}$ is 1.3 larger than the capacity at $25^{\circ} \mathrm{C}$ for the same specific current. Also, at $0{ }^{\circ} \mathrm{C}$ the $\mathrm{Zn}|| \mathrm{few}$ layer $\mathrm{Bi}_{2} \mathrm{Se}_{3}$ cell shows capacity retention of $94.6 \%$ after 2000 cycles at $1 \mathrm{Ag}^{-1}$. This behaviour is related to the fact that the $\mathrm{Zn}$-ion uptake in the few-layer $\mathrm{Bi}_{2} \mathrm{Se}_{3}$ is higher at low temperatures, e.g., almost four $\mathrm{Zn}^{2+}$ at $25^{\circ} \mathrm{C}$ and six $\mathrm{Zn}{ }^{2+}$ at $-20^{\circ} \mathrm{C}$. We demonstrate that the unusual performance improvements at low temperatures are only achievable with the few-layer $\mathrm{Bi}_{2} \mathrm{Se}_{3}$ rather than bulk $\mathrm{Bi}_{2} \mathrm{Se}_{3}$. We also show that the favourable low-temperature conductivity and ion diffusion capability of few-layer $\mathrm{Bi}_{2} \mathrm{Se}_{3}$ are linked with the presence of topological surface states and weaker lattice vibrations, respectively.

\footnotetext{
${ }^{1}$ Department of Materials Science and Engineering, City University of Hong Kong, Hong Kong, China. ${ }^{2}$ Institute of Microstructure and Properties of Advanced Materials, Beijing University of Technology, Beijing, China. ${ }^{3}$ International Center for Quantum Design of Functional Materials (ICQD), Hefei National Laboratory for Physical Sciences at the Microscale, Department of Physics, University of Science and Technology of China, Hefei, China. ${ }^{4}$ Department of Materials Science and Engineering, Southern University of Science and Technology, Shenzhen, China. ${ }^{5}$ School of Advanced Materials and Nanotechnology,

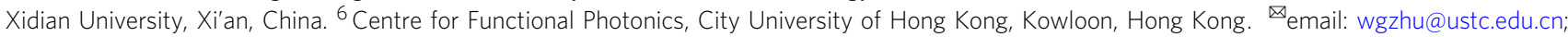
liuws@sustech.edu.cn; cy.zhi@cityu.edu.hk
} 
$\mathrm{P}$ erformance loss or failure occurs in nearly all types of cell systems (e.g. lithium/sodium/magnesium/zinc ion cell) in cold climates ${ }^{1-3}$. Advanced batteries imperatively need powerful energy density and excellent lifespan, even at subzero temperatures. Substantial effort has been devoted to investigating cell degradation at low temperature and proposing approaches for performance enhancement ${ }^{4,5}$. Several mechanisms are generally responsible for poor cell performance at low temperatures: (a) a reduced rate of ion transfer in the electrode materials; (b) lowerthan-usual electronic conductivity of the electrodes, especially for the widely used metal oxide electrodes; (c) lower-than-usual ionic conductivity of the electrolyte; and (d) sluggish charge-transfer kinetics induced by a decreased rate of chemical reactions. Fading electrochemical performance at low temperatures can be mitigated by introducing electrolyte additives ${ }^{6}$, coating surfaces with some material that is highly electronically conductive ${ }^{7,8}$, and heteroatom doping 9,10 , but the attenuation is inevitable, and to date the highest retention of $86 \%$ at $-25^{\circ} \mathrm{C}$ for a sodium ion cell is achieved by Goodenough's group using an organic electrolyte ${ }^{5}$. Although this progress is valuable, for a cell required to operate over a long period in a cold climate, performance degradation remains unavoidable ${ }^{5}$. In addition, previously proposed methods of low-temperature cell performance enhancement largely focus on electrolyte modification, which cannot solve the sluggish kinetics of electrode reactions.

Recently, a family of materials, namely topological insulators with unique thermal and electrical properties, gain widespread interests $^{11,12}$. These particular insulators have exotic metallic states formed by topological protection; their interiors function as insulators, but their surfaces act as conductors because their electrons are subject to strong spin-orbit interaction existing on their electrons ${ }^{13}$. Moreover, topological effects give these materials an inherent advantage: their properties are constant under any deformations. $\mathrm{Bi}_{2} \mathrm{Se}_{3}$, a topological insulator with a $0.3-\mathrm{eV}$ nontrivial bulk gap and superficial single Dirac cone, is formed by periodic layers composed of five atomic planes (Se-Bi-Se-Bi-Se; namely, a quintuple layer denoted QL) connected through van der Waals forces; numerous unoccupied tetrahedral and octahedral exist between the Se atomic planes and result in the material's potential as an intercalating cathode in batteries ${ }^{14,15}$. Especially, for low-dimensional $\mathrm{Bi}_{2} \mathrm{Se}_{3}$, the reduced concentration of bulk carriers highlights the contribution of conductivity from surface topological states. Particularly, the conductivity of most of the $\mathrm{Bi}_{2} \mathrm{Se}_{3}$ nanoribbon devices increases as temperature goes down ${ }^{16}$, and this metallic behavior provides an opportunity to circumvent the issue of cell electrodes operating at low temperatures. As topological surface states of $\mathrm{Bi}_{2} \mathrm{Se}_{3}$ protected by time inversion symmetry are robust at near ambient temperatures with exposure to liquids ${ }^{17-22}$, topological quantum states of $\mathrm{Bi}_{2} \mathrm{Se}_{3}$ have potential applications in cell environments.

Herein, we report an aqueous $\mathrm{Zn}$ ion cell (AZIB) consisting of a few QLs of $\mathrm{Bi}_{2} \mathrm{Se}_{3}$ nanosheets $\left(\mathrm{E}-\mathrm{Bi}_{2} \mathrm{Se}_{3}\right)$ as the cathode, a $\mathrm{Zn}$ anode, and an antifreeze polyacrylamide (PAM) hydrogel electrolyte with highly concentrated salts incorporated along with ethylene glycol (denoted HC-EGPAM). Bulk $\mathrm{Bi}_{2} \mathrm{Se}_{3}$ powder (P$\mathrm{Bi}_{2} \mathrm{Se}_{3}$ ) is readily exfoliated into $\mathrm{E}-\mathrm{Bi}_{2} \mathrm{Se}_{3}$ through hydrothermal intercalation to enhance the coupling advantage in topological surface states. Surprisingly, the $\mathrm{Zn} \| \mathrm{E}-\mathrm{Bi}_{2} \mathrm{Se}_{3}$ cell exhibits abnormally low-temperature performance (a capacity of up to $524 \mathrm{mAh} \mathrm{g}^{-1}$ at $-20^{\circ} \mathrm{C}$ and $0.3 \mathrm{~A} \mathrm{~g}^{-1}$ ) that is even better than its performance at $25^{\circ} \mathrm{C}$ (a capacity of $327 \mathrm{mAh} \mathrm{g}^{-1}$ at $0.3 \mathrm{~A} \mathrm{~g}^{-1}$ ) and all previously reported measurements of low-temperature batteries. Even at $-40^{\circ} \mathrm{C}$, the capacity retentions remain to 106 and $113 \%$ compared to the capacities at $25^{\circ} \mathrm{C}$. Specifically, per molecular $\mathrm{E}_{-} \mathrm{Bi}_{2} \mathrm{Se}_{3}$ holds up to four $\mathrm{Zn}^{2+}$ on discharge at $25^{\circ} \mathrm{C}$ and six $\mathrm{Zn}^{2+}$ at $-20^{\circ} \mathrm{C}$ along with greatly increased unit cell parameter $(c)$. The unusual performance is attributed to the topological nature of $\mathrm{E}_{-} \mathrm{Bi}_{2} \mathrm{Se}_{3}$ improving kinetics of the cell reactions at lower temperatures. This is confirmed in this study by the observed higher electronic conductivity and good ion diffusion of the topological $\mathrm{E}_{-} \mathrm{Bi}_{2} \mathrm{Se}_{3}$ cathode at lower temperatures. Interestingly, after intercalation of $\mathrm{Zn}^{2+}$ into the $\mathrm{E}-\mathrm{Bi}_{2} \mathrm{Se}_{3}$ cathode, enhanced contribution of trivial metal states for $\mathrm{Zn}_{x} \mathrm{Bi}_{2} \mathrm{Se}_{3}$ is revealed and proved theoretically and experimentally by conducting an electrical behavior test, density-functional theory (DFT) calculation, and ab initio molecular dynamics (MD) simulation. We believe that the developed topological insulator electrode and unusually better cell performance at lower temperatures will provide opportunities for producing batteries that will operate for long periods in cold climates.

\section{Results}

Characterization of $\mathbf{P}-\mathbf{B i}_{2} \mathrm{Se}_{3}$ and $\mathbf{E}-\mathbf{B i}_{2} \mathbf{S e}_{3}$. A few QLs of $\mathrm{E}-\mathrm{Bi}_{2} \mathrm{Se}_{3}$ has been testified the existence of coupling-enhanced topological surface states in contrast to the bulk $\mathrm{P}-\mathrm{Bi}_{2} \mathrm{Se}_{3}$. The single-phase rhombohedral $\mathrm{P}-\mathrm{Bi}_{2} \mathrm{Se}_{3}$ structure and $D_{3 d}^{5}(R \overline{3} m)$ space group of the prepared samples are confirmed using X-ray powder diffraction (XRD; Fig. 1a). Hydrothermal intercalation is used to exfoliate the $\mathrm{P}-\mathrm{Bi}_{2} \mathrm{Se}_{3}$ into $\mathrm{E}-\mathrm{Bi}_{2} \mathrm{Se}_{3}$ (Supplementary Fig. 1). Although $\mathrm{LiOH}$ is involved during the exfoliation, analyses of $\mathrm{Bi}$ and $\mathrm{Se}$ ions by inductively coupled plasma atomic emission spectrometry (ICP-AES) and $\mathrm{Li}$ ion by ICP-mass spectrometry (ICP-MS) evidence the $\mathrm{Li} / \mathrm{Bi} / \mathrm{Se}$ atomic ratio for the $\mathrm{E}-\mathrm{Bi}_{2} \mathrm{Se}_{3}$ sample is $0.00: 1.00: 1.48$, respectively, indicating the absence of $\mathrm{Li}$ in the final product (Supplementary Table 1). For the $\mathrm{E}-\mathrm{Bi}_{2} \mathrm{Se}_{3}$, exfoliation causes the number of stacking layers in one $\mathrm{Bi}_{2} \mathrm{Se}_{3}$ particle reduced, and the intensity of related host peaks (such as the (006) peak) is considerably lower than that in the $\mathrm{P}-\mathrm{Bi}_{2} \mathrm{Se}_{3}$ spectrum ${ }^{23}$. $\mathrm{E}-\mathrm{Bi}_{2} \mathrm{Se}_{3}$ lattice parameters of $a=4.14(3) \AA, \quad b=4.14(3) \AA$, and $c=28.67(4) \AA$ are obtained through Rietveld refinement, and these parameters favorably match the experimental profile displayed in Fig. 1b. The refined atomic models are illustrated in Fig. 1c and Supplementary Fig. 2 where the framework consists of covalently bonded QLs coupled through van der Waals interactions in the [001] direction, accommodating the intercalant at high density and providing large tunnels for ion diffusion at interstitial sites or interlayer galleries in the van der Waals gap ${ }^{24}$. Rietveld refinement of the XRD pattern of $\mathrm{P}-\mathrm{Bi}_{2} \mathrm{Se}_{3}$ are likewise shown in 3, and the refined structure parameters are listed in Supplementary Table 2. The transmission electron microscopy (TEM) analysis of $\mathrm{P}-\mathrm{Bi}_{2} \mathrm{Se}_{3}$ presented in Supplementary Fig. 4a indicates irregular granules ranging in size from $200 \mathrm{~nm}$ to $1 \mu \mathrm{m}$. The corresponding selected area electron diffraction (SAED) spot pattern indicates that the $\mathrm{P}-\mathrm{Bi}_{2} \mathrm{Se}_{3}$ is polycrystalline (Supplementary Fig. $4 \mathrm{~b}$ ). After exfoliation, ultrathin and stacked nanosheets with ripples of $\mathrm{E}-\mathrm{Bi}_{2} \mathrm{Se}_{3}$ and sized within $1 \mu \mathrm{m}$ are obtained (Fig. 1d), and a typical hexagonal SAED pattern of $\mathrm{E}-\mathrm{Bi}_{2} \mathrm{Se}_{3}$ consistent with the (110) and (300) planes is distinctly observed, confirming the high level of single crystallinity. The high-angle annular dark-field scanning transmission electron microscopy (HAADF-STEM) image of $\mathrm{E}_{-} \mathrm{Bi}_{2} \mathrm{Se}_{3}$ recorded along the [010] zone axis (Fig. 1e) is a magnified view from the A region of Supplementary Fig. 5a, where 1 QL is well assigned to the layered structure. The corresponding electron energy loss spectroscopy (EELS) elemental maps confirm the uniform distribution of Se and Bi (Fig. 1e). Magnified view of a rectangular area in Fig. 1e shows consistency with the $\mathrm{E}-\mathrm{Bi}_{2} \mathrm{Se}_{3}$ rhombohedral structure at the atomic resolution (Supplementary Fig. 5b-d and Fig. 1f $)^{25,26}$. A structural model is shown on the left of the HAADF image. Figure $1 \mathrm{~g}$ shows the intensity line scan along the orange dashed line in the HAADF image. Clear peaks 

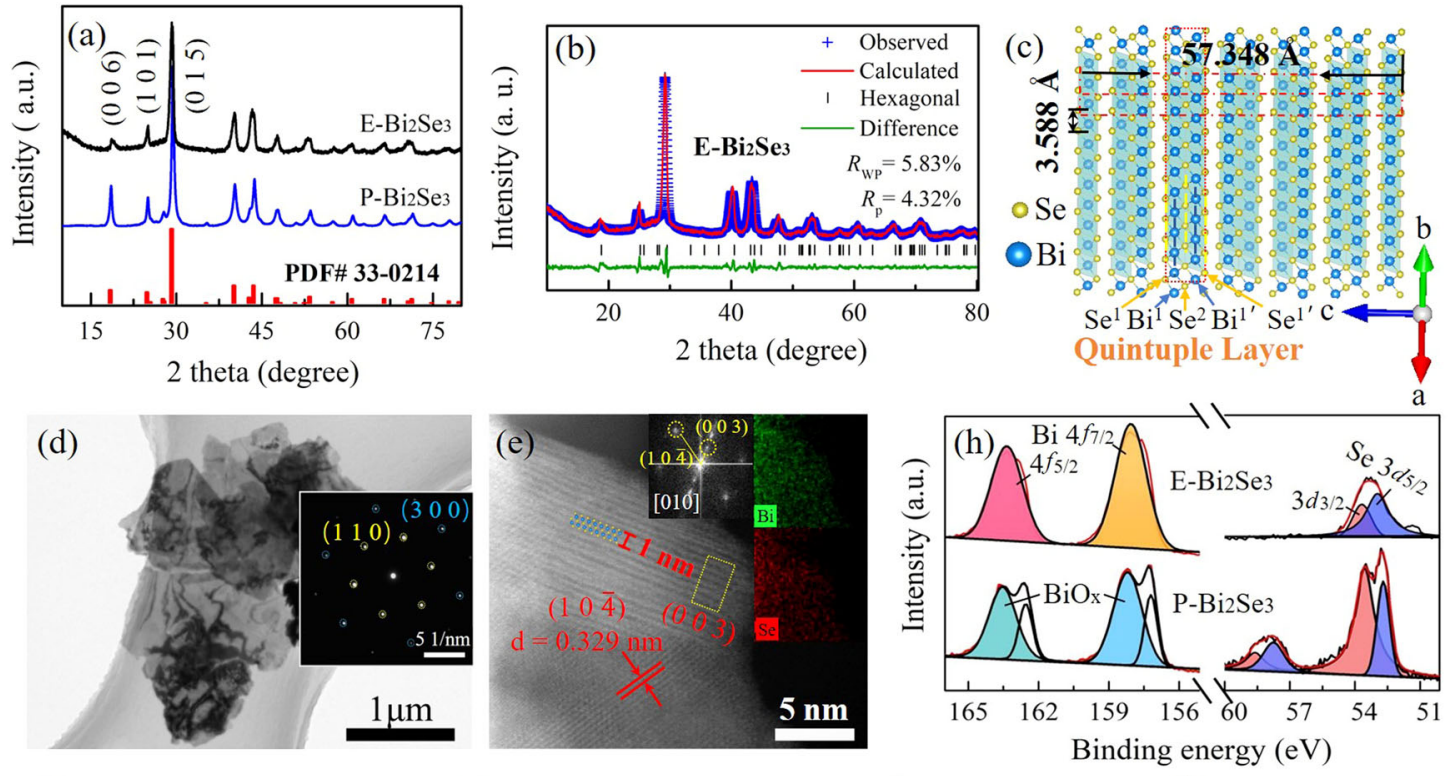

(f)

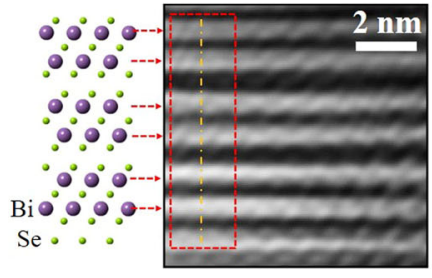

(g)

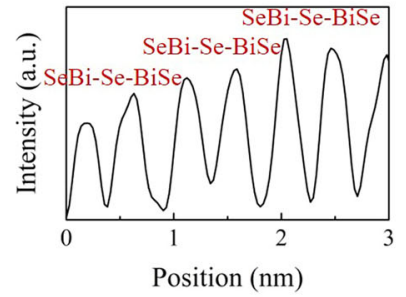

(i)

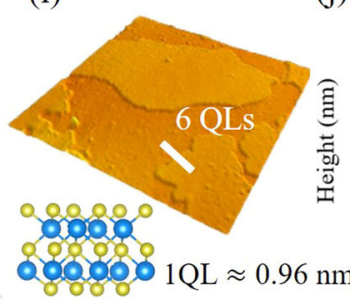

(j)

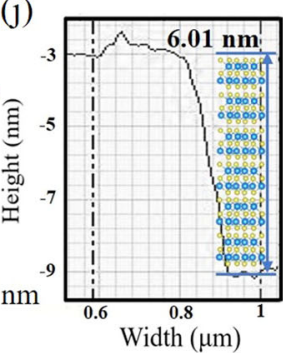

Fig. 1 Structural and morphological characterization of prepared $\mathbf{P}-\mathbf{B i}_{\mathbf{2}} \mathbf{S e}_{\mathbf{3}}$ and $\mathbf{E}-\mathbf{B i}_{\mathbf{2}} \mathbf{S e}_{\mathbf{3}}$. a XRD analyses of $\mathrm{P}-\mathrm{Bi}_{2} \mathrm{Se}_{3}$ and $\mathrm{E}-\mathrm{Bi}_{2} \mathrm{Se}_{3}$ (matched with powder diffraction file cards No. 00-033-0214). b Rietveld refinement of the XRD pattern of $\mathrm{E}-\mathrm{Bi}_{2} \mathrm{Se}_{3}$ with reliability factors $R_{\mathrm{wp}}$ and $R_{\mathrm{p}}$ of $5.83 \%$ and $4.32 \%$, respectively. $\mathbf{c}$ Layered crystal structure of $\mathrm{E}-\mathrm{Bi}_{2} \mathrm{Se}_{3}$ with quintuple layers aligned perpendicular to the trigonal c-axis. The dashed red square indicates a quintuple layer in the $\mathrm{Se}^{1}-\mathrm{Bi}^{1}-\mathrm{Se}^{2}-\mathrm{Bi}^{1}-\mathrm{Se}^{1 /}$ sequence, and the dimensions shown here are calculated from the lattice constants. $\mathbf{d}$ TEM image of $\mathrm{E}-\mathrm{Bi}_{2} \mathrm{Se}_{3}$ and corresponding SAED pattern. e HAADF- STEM image of E-Bi $\mathrm{Se}_{3}$ and its corresponding EELS elemental mappings along [010] zone axis. $\mathbf{f} \mathrm{A}$ magnified view of the yellow rectangular area in e with the $\mathrm{E}_{-} \mathrm{Bi}_{2} \mathrm{Se}_{3}$ crystal structure. $\mathbf{g} \mathrm{An}$ intensity profile from orange line in $\mathbf{f}$. $\mathbf{h}$ XPS spectra of $\mathrm{Bi} 4 f$ and $\mathrm{Se} 3 d$ signals for $\mathrm{P}-\mathrm{Bi}_{2} \mathrm{Se}_{3}$ and $\mathrm{E}-\mathrm{Bi}_{2} \mathrm{Se}_{3}$. $\mathbf{i}$ Typical AFM image of individual $\mathrm{E}-\mathrm{Bi}_{2} \mathrm{Se}_{3}$ and $\mathbf{j}$ corresponding height profile.

are observed due to the Se-Bi-Se atoms column. We averaged several plots across Se-Bi-Se cluster along pink dashed lines (Supplementary Fig. 5e). Assume the atom is a Gaussian shape. The averaged plot (average of 8 line profiles) is fitted with Gaussians (Supplementary Fig. 5f). Two Se atoms do not distribute symmetrically around $\mathrm{Bi}$ site. The phenomena are due to that the atomic configuration at different areas may have certain distortion after HEMM and hydrothermal exfoliating processes as capturing the atomic-scaled HAADF image along [010] zone axis (see Supplementary Fig. 5 for details). Two peaks together in Fig. $1 \mathrm{~g}$ corresponds to a QL of Se-Bi-Se-Bi-Se with a thickness approaching $1 \mathrm{~nm}$, confirming the ordered arrangement of QLs originating from the layered structure. High-resolution HAADFSTEM image from the B region of Supplementary Fig. 5a shown in Supplementary Fig. $5 \mathrm{~g}$ has a (003) crystal plane orientation confirmed by corresponding Fourier transform (FT) pattern, which highlights the lamellar structure of $\mathrm{E}_{-} \mathrm{Bi}_{2} \mathrm{Se}_{3}$ (Supplementary Fig. 5h). The electron energy loss spectrum of $\mathrm{E}-\mathrm{Bi}_{2} \mathrm{Se}_{3}$ shows that $\mathrm{E}-\mathrm{Bi}_{2} \mathrm{Se}_{3}$ does not contain $\mathrm{Li}$ as there is no peak at $55 \mathrm{eV}$ in Supplementary Fig. 5i. X-ray photoelectron spectroscopy (XPS) also indicate the composition of $\mathrm{P}-\mathrm{Bi}_{2} \mathrm{Se}_{3}$ and $\mathrm{E}-\mathrm{Bi}_{2} \mathrm{Se}_{3}$ (Supplementary Fig. 6a). No liquid intercalation was observed (Supplementary Fig. 6b). The high-resolution spectra reveal the valence states of the $\mathrm{Bi}$ and $\mathrm{Se}$ (Fig. 1h). The $\mathrm{Bi} 4 f$ spectrum of $\mathrm{E}-\mathrm{Bi}_{2} \mathrm{Se}_{3}$ has two peaks at 163.37 and $158.02 \mathrm{eV}$, corresponding to the $\mathrm{Bi}$ $4 f_{5 / 2}$ and $4 f_{7 / 2}$ binding energies attributable to $\mathrm{Bi}_{2} \mathrm{Se}_{3}$, respectively, whereas deconvolution of the $\mathrm{Bi} 4 f$ core-level peaks in the $\mathrm{P}-\mathrm{Bi}_{2} \mathrm{Se}_{3}$ spectrum indicates that the $\mathrm{Bi} 4 f_{5 / 2}$ and $4 f_{7 / 2}$ peaks are shifted to higher energies by $0.9 \mathrm{eV}$, which is likely attributable to the formation of oxides $\left(\mathrm{BiO}_{x}\right)$, as discovered in a previous study on $\mathrm{Bi}_{2} \mathrm{Se}_{3}$ nanowires signifying higher oxidation states than those of $\mathrm{E}-\mathrm{Bi}_{2} \mathrm{Te}_{3}{ }^{27}$. Moreover, one peak of Se $3 d$ level for $\mathrm{E}-\mathrm{Bi}_{2} \mathrm{Se}_{3}$ reveal the contributions of $\mathrm{Se}^{2-}$ in $\mathrm{Bi}_{2} \mathrm{Se}_{3}$ from the Se $3 d_{5 / 2}$ level at binding energy of $52.85 \mathrm{eV}$, and $\mathrm{Se} 3 d_{3 / 2}$ level at $53.74 \mathrm{eV}$, and a similar phenomenon emerges in $\mathrm{P}_{-} \mathrm{Bi}_{2} \mathrm{Se}_{3}$. The blueshift of the $\mathrm{Se}$ $3 d$ peak at $58.2 \mathrm{eV}$ in $\mathrm{P}-\mathrm{Bi}_{2} \mathrm{Se}_{3}$ is attributed to amorphous $\mathrm{SeO}_{2}$ introduced during HEMM process ${ }^{28,29}$ (Supplementary Fig. 7). After washing with tetramethylammonium hydroxide (TMAH)/ $\mathrm{NaOH} / \mathrm{NaCl}$ aqueous solution and DI water, $\mathrm{SeO}_{2}$ impurity can be fully removed. Figure $1 \mathrm{i}$ presents a typical atomic force microscopy (AFM) image showing the smooth surface of $\mathrm{E}-\mathrm{Bi}_{2} \mathrm{Se}_{3}$, and Fig. $1 \mathrm{j}$ shows the corresponding height profile, revealing that the thickness of $\mathrm{E}_{-} \mathrm{Bi}_{2} \mathrm{Se}_{3}$ is approximately $6 \mathrm{~nm}$ and that the material thus consists of 6 QLs given than the thickness of a QL is approximately $0.96 \mathrm{~nm}^{30}$. The thickness of numerous flakes is calculated from the AFM image in Supplementary Fig. 8, the average thickness is statistically estimated to be $6 \mathrm{~nm}$.

Electrochemical performance comparison in $\mathrm{Zn} \| \mathrm{P}-\mathrm{Bi}_{2} \mathrm{Se}_{3}$ and $\mathbf{Z n} \| \mathbf{E}-\mathbf{B i}_{2} \mathbf{S e}_{3}$ cells. The temperature-dependent electrochemical 


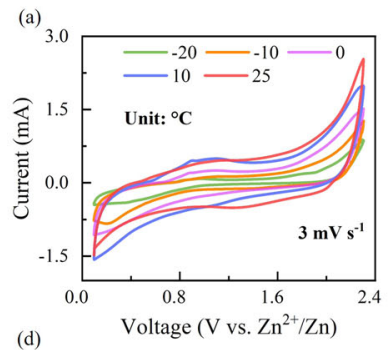

(b)
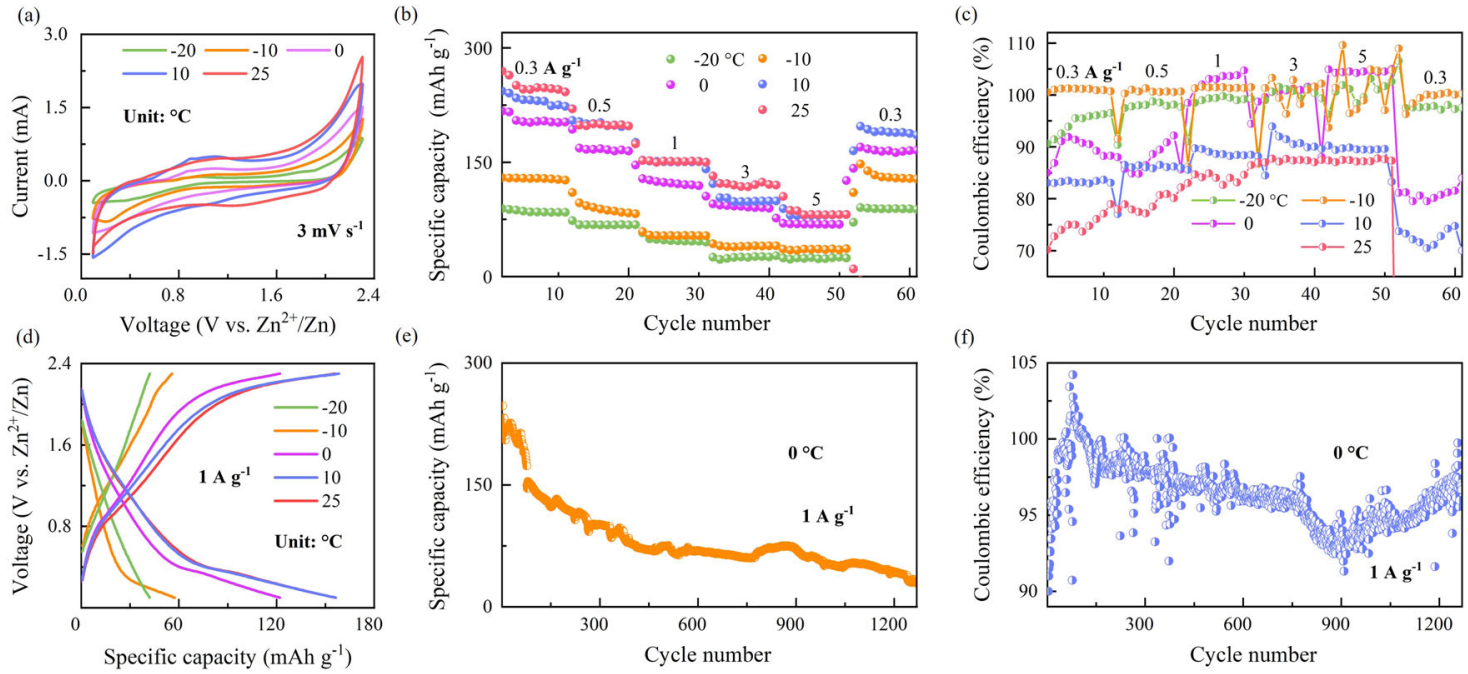

Fig. 2 Electrochemical performance of the rechargeable quasi-solid $\mathrm{Zn}|| \mathrm{P}-\mathrm{Bi}_{2} \mathrm{Se}_{3}$ cells over the temperature range $-\mathbf{2 0}$ to $25^{\circ} \mathrm{C}$. a $\mathrm{CVs}$ for quasi-solid $\mathrm{Zn} \| \mathrm{P}-\mathrm{Bi}_{2} \mathrm{Se}_{3}$ cells at different temperatures. $\mathbf{b}$ Rate capability and corresponding CE (c) and GCD profiles (d) of the quasi-solid AZIB at different temperatures. e Long-cycle performance and corresponding $\mathrm{CE}(\mathbf{f})$ at $0^{\circ} \mathrm{C}$.

performance of the rechargeable $\mathrm{Zn}|| \mathrm{P}-\mathrm{Bi}_{2} \mathrm{Se}_{3}$ and $\mathrm{Zn}|| \mathrm{E}-\mathrm{Bi}_{2} \mathrm{Se}_{3}$ cells is characterized using HC-EGPAM as the electrolyte. The preparation and characterization of HC-EGPAM hydrogel electrolyte are detailed in Supplementary Fig. 9. The HC-EGPAM hydrogel has high adhesiveness, favorable freezing tolerance, and flexibility even at $-35^{\circ} \mathrm{C}$ (Supplementary Fig. $\left.9 \mathrm{~h}-\mathrm{j}\right)^{6}$. The ionic conductivity of HC-EGPAM hydrogel is much higher than that of PAM containing highly concentrated salts (HC-PAM) at low temperatures (Supplementary Fig. 9f). However, when the temperature is decreased from 25 to $-20{ }^{\circ} \mathrm{C}, 50 \%$ of the ionic conductivity of HC-EGPAM is still lost (from 7.85 to $3.90 \mathrm{~ms} \mathrm{~cm}^{-1}$ ).

We first test the electrochemical performance of the quasisolid $\mathrm{Zn} \| \mathrm{P}-\mathrm{Bi}_{2} \mathrm{Se}_{3}$ cell, in which the $\mathrm{P}-\mathrm{Bi}_{2} \mathrm{Se}_{3}$ exhibits limited topological insulating states. Figure $2 \mathrm{a}$ shows a typical cyclic voltammogram $(\mathrm{CV})$ with weakened intensity at decreased temperature. The temperature-dependent rate performance is illustrated in Fig. 2b. At $25^{\circ} \mathrm{C}$, capacities values of $249,199,152$, 129 , and $88 \mathrm{mAh} \mathrm{g}^{-1}$ are obtained at current rates of 0.3 , $0.5,1,3$, and $5 \mathrm{Ag}^{-1}$, respectively. At lower temperature, the reversible capacity of the $\mathrm{Zn} \| \mathrm{P}-\mathrm{Bi}_{2} \mathrm{Se}_{3}$ cell is severely decreased. At $0.3 \mathrm{~A} \mathrm{~g}^{-1}$, the $\mathrm{Zn} \| \mathrm{P}-\mathrm{Bi}_{2} \mathrm{Se}_{3}$ cell maintains reversible capacities values of $231,205,130$, and $87 \mathrm{mAh} \mathrm{g}^{-1}$ at $10,0,-10$, and $-20{ }^{\circ} \mathrm{C}$, respectively, which are $92 \%, 82 \%, 52 \%$, and $35 \%$ of the capacities delivered at $25^{\circ} \mathrm{C}$, respectively. At higher temperature or lower specific current, characteristic low coulombic efficiency (CE) is noted on account of the irreversible side reaction (Fig. 2c) ${ }^{31}$. Figure $2 \mathrm{~d}$ displays the corresponding galvanostatic charge/discharge (GCD) curves obtained at various temperatures from -20 to $25^{\circ} \mathrm{C}$ at $1 \mathrm{~A} \mathrm{~g}^{-1}$. Discharge capacities of $42,57,122$, 156 , and $156.3 \mathrm{mAh}^{-1}$ are obtained at temperatures of -20 , $-10,0,10$, and $25^{\circ} \mathrm{C}$, respectively. The GCD profile obtained at $-20^{\circ} \mathrm{C}$ is almost a straight line, which is attributable to the sluggish $\mathrm{Zn}^{2+}$-transport kinetics ${ }^{32}$. The $\mathrm{Zn} \| \mathrm{P}-\mathrm{Bi}_{2} \mathrm{Se}_{3}$ cell exhibits poor cycling performance at a low temperature of $0{ }^{\circ} \mathrm{C}$ in Fig. 2e, f: the capacity retention is less than $16 \%$ after 1200 cycles at $1 \mathrm{~A} \mathrm{~g}^{-1}$, in which $\mathrm{P}-\mathrm{Bi}_{2} \mathrm{Se}_{3}$ electrode delamination leads to the cell failure ${ }^{33}$. Our observation clearly indicates that even when an anti-freeze electrolyte is employed, performance degradation of $\mathrm{Zn} \| \mathrm{P}-\mathrm{Bi}_{2} \mathrm{Se}_{3}$ at low temperature is unavoidable, which is similar to other reported cells. The working mechanism of $\mathrm{P}-\mathrm{Bi}_{2} \mathrm{Se}_{3}$ is studied in Supplementary Fig. 10, and the capacitive behavior with poor bulk diffusion is observed.
We further evaluate the electrochemical performance of the asprepared $\mathrm{E}-\mathrm{Bi}_{2} \mathrm{Se}_{3}$ cathodes in an $\mathrm{AZIB}$ at different temperatures with the $\mathrm{E}_{-} \mathrm{Bi}_{2} \mathrm{Se}_{3}$ exhibiting enhanced topological states ${ }^{16,34}$. Unlike what we have observed for the $\mathrm{Zn} \| \mathrm{P}-\mathrm{Bi}_{2} \mathrm{Se}_{3}$ cell, as the temperature is decreasing, the cathodic peaks shift to higher potential and anodic peaks shift to lower potential, which can be ascribed to reduced polarization (Fig. 3a) ${ }^{35}$. Exceptionally, the area of redox peaks is remarkably enlarged at lower temperature, indicating higher reaction kinetics of $\mathrm{E}-\mathrm{Bi}_{2} \mathrm{Se}_{3}$ electrodes at low temperature than at $25^{\circ} \mathrm{C}^{36}$. Figure $3 \mathrm{~b}, \mathrm{c}$ depict the good rate capability of $\mathrm{Zn} \| \mathrm{E}-\mathrm{Bi}_{2} \mathrm{Se}_{3}$ cells at -20 to $25^{\circ} \mathrm{C}$. Unlike all previously reported cells, including the $\mathrm{Zn} \| \mathrm{P}-\mathrm{Bi}_{2} \mathrm{Se}_{3}$ cells for which attenuation inevitably occurs at low temperatures, the $\mathrm{Zn} \|$ E- $\mathrm{Bi}_{2} \mathrm{Se}_{3}$ cells anomaly deliver better performances at lower temperatures. At $-20^{\circ} \mathrm{C}$, discharge specific capacities of 526.3, $400.9,301.3$, and $206.1 \mathrm{mAh} \mathrm{g}^{-1}$ are obtained at specific currents of $0.3,0.5,1.0$, and $3.0 \mathrm{~A} \mathrm{~g}^{-1}$, respectively. Compared with the capacities of $326.7,278,231$, and $159 \mathrm{mAh} \mathrm{g}^{-1}$ at $25^{\circ} \mathrm{C}$, the capacity retention values at $-20^{\circ} \mathrm{C}$ are $161 \%, 144 \%, 130 \%$, and $129.6 \%$, respectively. When the current rate returns to $0.3 \mathrm{~A} \mathrm{~g}^{-1}$ from $3 \mathrm{Ag}^{-1}$, discharge capacities of 499 (the rate capacity retention of $95 \%), 468,405,335$, and $317 \mathrm{mAh} \mathrm{g}^{-1}$ are recovered at $-20,-10,0,10$, and $25^{\circ} \mathrm{C}$, respectively. The corresponding GCD profiles at different temperatures at $1 \mathrm{~A} \mathrm{~g}^{-1}$ are displayed in Fig. 3d, all containing a discharge plateau at approximate $1.6 \mathrm{~V}$ and a subsequent slope at around $1.0 \mathrm{~V}$. In sharp contrast to the $\mathrm{Zn} \| \mathrm{P}-\mathrm{Bi}_{2} \mathrm{Se}_{3}$ cells, the $\mathrm{Zn} \| \mathrm{E}-\mathrm{Bi}_{2} \mathrm{Se}_{3}$ cells exhibit surprisingly enhanced discharge capacity $\left(269 \mathrm{mAh} \mathrm{g}^{-1}\right)$ and cycling capacity retention $\left(94.6 \%\right.$ after 2000 cycles at $0{ }^{\circ} \mathrm{C}$ ) at $1 \mathrm{~A} \mathrm{~g}^{-1}$ with a high CE nearly $100 \%$ (Fig. 3e, f). The capacity in Fig. 3e sharply increases in the first tens cycles due to the activation of the electrode. In addition, the polarization of the cell is negligible, being as low as $0.08 \mathrm{~V}$ at $-20^{\circ} \mathrm{C}$. We further extend the temperature range (Supplementary Fig. 11). At the temperature ranging from $-20^{\circ} \mathrm{C}$ to $-50{ }^{\circ} \mathrm{C}$ (or from $50{ }^{\circ} \mathrm{C}$ to $30^{\circ} \mathrm{C}$ ), electrolyte has a greater influence on the cell performance (Supplementary Fig. 11a-d) as the ionic conductivity may remarkably decrease with the declined temperature ${ }^{37}$. For the region from $30{ }^{\circ} \mathrm{C}$ to $-20^{\circ} \mathrm{C}$, the contribution of $\mathrm{E}-\mathrm{Bi}_{2} \mathrm{Se}_{3}$ electrode to the cell performance enhancement is greater than that of the electrolyte (Supplementary Fig. 11e). Supplementary Figure $11 \mathrm{f}$ summarizes capacity retention of $\mathrm{Zn} \| \mathrm{E}-\mathrm{Bi}_{2} \mathrm{Se}_{3}$ cells at 

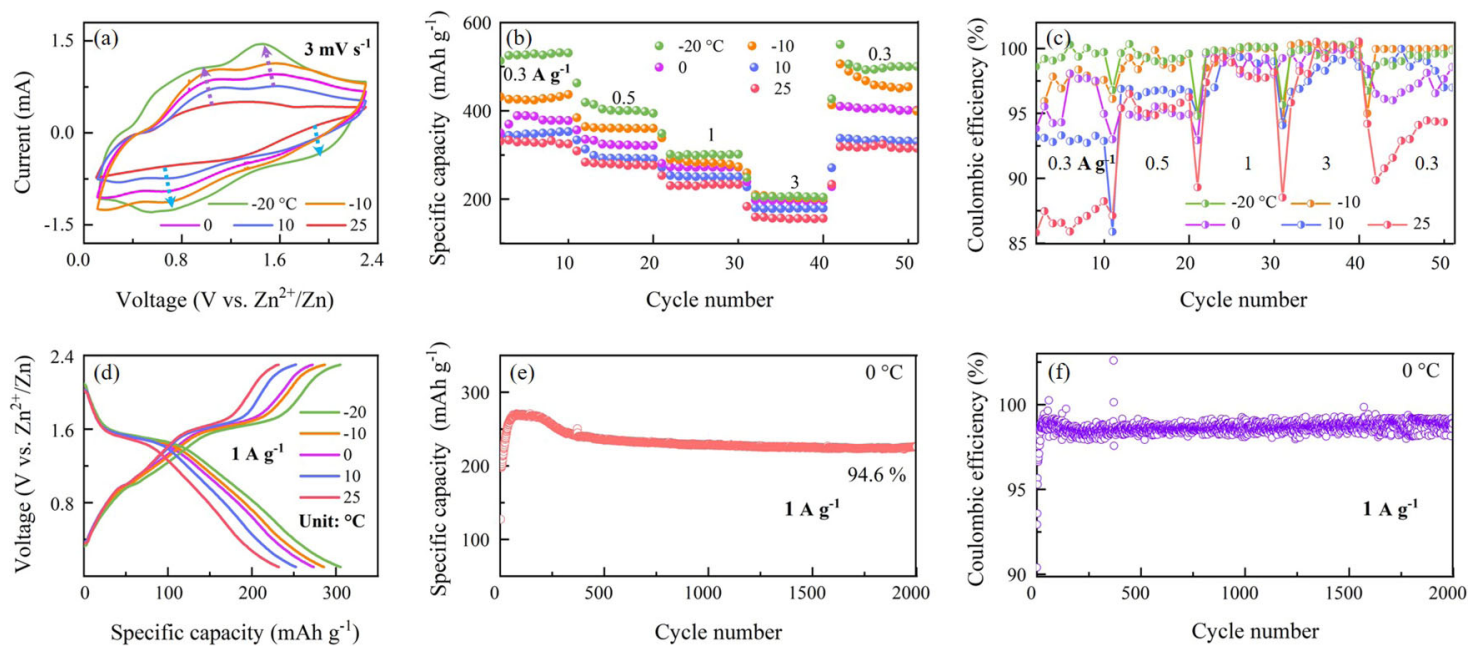

Fig. 3 Electrochemical performance of the rechargeable quasi-solid $\mathrm{Zn}|| \mathrm{E}-\mathrm{Bi}_{2} \mathrm{Se}_{3}$ cells over the temperature range -20 to $25{ }^{\circ} \mathrm{C}$. a $\mathrm{CVS}$ of quasi-solid $\mathrm{Zn} \| \mathrm{E}-\mathrm{Bi}_{2} \mathrm{Se}_{3}$ cells at different temperatures. b Rate capability and corresponding CE (c) and GCD profiles (d) of the quasi-solid AZIB at different temperatures. e Long-cycle discharge capacity and corresponding $\mathrm{CE}(\mathbf{f})$ at $\mathrm{O}^{\circ} \mathrm{C}$.
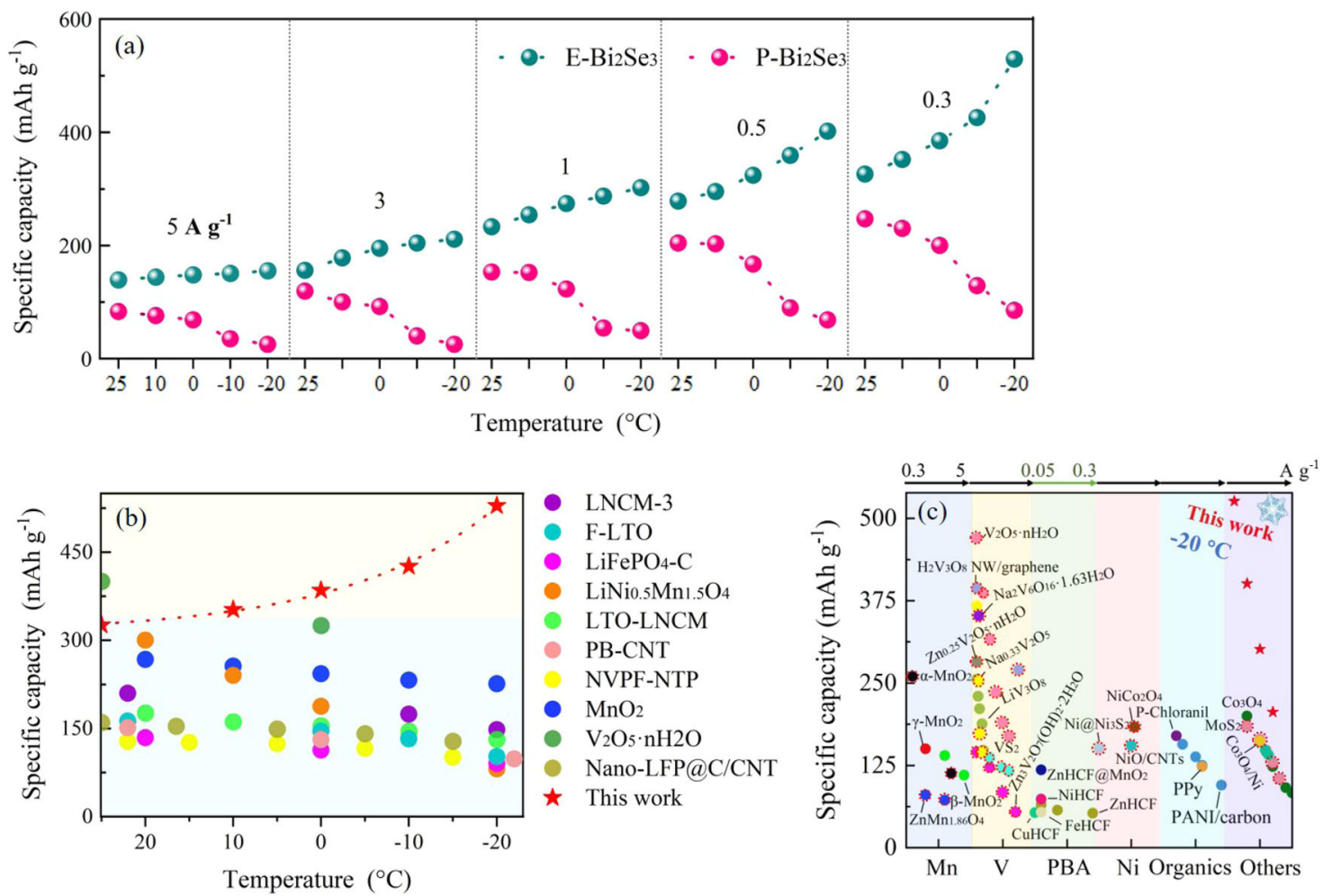

Fig. 4 Comparison of specific capacity of this work with that of previous reports. a Comparison of discharge specific capacity versus temperature of $\mathrm{Zn} \|$ $\mathrm{P}-\mathrm{Bi}_{2} \mathrm{Se}_{3}$ and $\mathrm{Zn} \| \mathrm{E}-\mathrm{Bi}_{2} \mathrm{Se}_{3}$ cells at various current rates and temperatures. $\mathbf{b}$ Specific capacity versus temperature of various low-temperature cells including lithium/sodium/zinc ion cells, among which LNCM-37, F-LTO, LTO-LNCM, PB-CNT, NVPF-NTP, and LFP stand for $\mathrm{LiNi}_{0.6} \mathrm{Co}_{0.2} \mathrm{Mn}_{0.2} \mathrm{O}_{2}, \mathrm{fluorinated}$ $\mathrm{Li}_{4} \mathrm{Ti}_{5} \mathrm{O}_{12}{ }^{9}, \mathrm{Li}_{4} \mathrm{Ti}_{5} \mathrm{O}_{12} / \mathrm{Li}\left[\mathrm{Ni}_{0.45} \mathrm{Co}_{0.1} \mathrm{Mn}_{1.45}\right] \mathrm{O}_{4}{ }^{3}$, Prussian blue-carbon nanotubes ${ }^{5}, \mathrm{Na}_{3} \mathrm{~V}_{2}\left(\mathrm{PO}_{4}\right)_{2} \mathrm{O}_{2} \mathrm{~F}$ nanotetraprisms ${ }^{32}$, and $\mathrm{LiFePO}_{4}{ }^{39}$, respectively. c Comparison of specific capacity between the present $\mathrm{E}-\mathrm{Bi}_{2} \mathrm{Se}_{3}$ cathode at $-20^{\circ} \mathrm{C}$ and representative cathodes in $\mathrm{AZIBs}$ at room temperature and various current rates. All the current rates herein are in the range 0.3-5.0 A g ${ }^{-1}$ except for Prussian blue analogs (PBAs), for which they are 0.05-3.00 A g ${ }^{-1}$. The exfoliated and nanoscale electrodes are circled with dotted lines.

various temperatures and current rates compared to the corresponding discharge capacities at $25^{\circ} \mathrm{C}$. Remarkably, even at $-40^{\circ} \mathrm{C}$ the capacity retentions at 1 and $3 \mathrm{~A} \mathrm{~g}^{-1}$ remain to be over $100 \%$ (106 and $113 \%$, respectively). The $\mathrm{Zn} \| \mathrm{E}-\mathrm{Bi}_{2} \mathrm{Se}_{3}$ cells still deliver discharge capacities of $280,245,206,140$, and $113 \mathrm{mAh} \mathrm{g}^{-1}$ at specific currents from 0.3 to $5 \mathrm{~A} \mathrm{~g}^{-1}$ at $-50{ }^{\circ} \mathrm{C}$ with record-high capacity retentions of $86,88,88,90$, and $81 \%$, respectively (Supplementary Fig. 11f).

Figure 4a and Supplementary Fig. 12a summarize comparisons of temperature-dependent discharge gravimetric and volumetric capacities of $\mathrm{Zn} \| \mathrm{E}-\mathrm{Bi}_{2} \mathrm{Se}_{3}$ and $\mathrm{Zn} \| \mathrm{P}^{-}-\mathrm{Bi}_{2} \mathrm{Se}_{3}$ cells at various current rates, respectively. Clearly, unlike the $\mathrm{Zn} \| \mathrm{P}-\mathrm{Bi}_{2} \mathrm{Se}_{3}$ with 
a degraded performance at lower temperatures, the specific capacity of $\mathrm{Zn}|| \mathrm{E}-\mathrm{Bi}_{2} \mathrm{Se}_{3}$ increases as the temperature decreases. To rule out the contribution from the electrolyte, we compare $\mathrm{Zn} \| \mathrm{MnO}_{2}$ cells using HC-EGPAM with other reported antifreeze hydrogel (Supplementary Fig. 12b), and also compare our topological insulator $\mathrm{E}-\mathrm{Bi}_{2} \mathrm{Se}_{3}$ electrode with $\mathrm{PBAs}$ and $\mathrm{MnO}_{2}$ electrodes in other antifreeze hydrogel electrolytes (Supplementary Fig. 12c, details of discussion are given in the Supporting Information). This anomalous low-temperature cell performance has also been observed in a $\mathrm{Na}_{3} \mathrm{VCr}\left(\mathrm{PO}_{4}\right)_{3}$ (NVCP) cathode ${ }^{38}$. However, it should be noted that this is because NVCP is not stable at a relatively high temperature $\left(30^{\circ} \mathrm{C}\right)$, leading to a poorer performance output at higher temperature. At low temperature, the high temperature induced irreversible electrochemical reaction can be suppressed in $\mathrm{NVCP}^{38}$. With a totally different mechanism, here exfoliation endows $\mathrm{Bi}_{2} \mathrm{Se}_{3}$ with large electrode/ electrolyte interfacial contact areas (reduced the ion diffusion length) and fast ion diffusion, which improves the cells performance. More importantly, exfoliation enhances the topological protection performance of the electrodes, significantly increasing electronic conductivity and boosting the electron transfer kinetics (Supplementary Fig. 13) ${ }^{13,16}$. What really gives the cell remarkably improved performance at low temperature is the synergistic effect of exfoliation and exfoliation-enhanced topological surface state. Compared with all other lowtemperature cells including lithium/sodium/zinc ion cells in aqueous $^{6,39}$ or organic $3,5,7,9,32,40,41$ electrolytes, as shown in Fig. $4 \mathrm{~b}$, the temperature-dependent capacity of $\mathrm{Zn} \| \mathrm{E}-\mathrm{Bi}_{2} \mathrm{Se}_{3}$ is among the best. Moreover, the variation trend of capacity versus temperature is clearly reversed. Figure $4 \mathrm{c}$ discloses the comparison profile of the dependence of specific capacity on current rate for the prepared $\mathrm{E}-\mathrm{Bi}_{2} \mathrm{Se}_{3}$ cathode and representative $\mathrm{Mn}^{42,43}, \mathrm{~V}^{44-48}$, and Ni-based cathodes ${ }^{49,50}, \mathrm{PBAs}^{51,52}$, organic cathodes ${ }^{35,53,54}$, and others ${ }^{55,56}$ in AZIBs. The Zn||E$\mathrm{Bi}_{2} \mathrm{Se}_{3}$ possesses the highest specific capacity of $526.3 \mathrm{mAh} \mathrm{g}^{-1}$ at $0.3 \mathrm{~A} \mathrm{~g}^{-1}$ at $-20^{\circ} \mathrm{C}$, which is even prominently outstrip those of the most room-temperature reports. The $\mathrm{E}_{-} \mathrm{Bi}_{2} \mathrm{Se}_{3}$ cathode is also amenable to high mass loadings of $1-4 \mathrm{mg} \mathrm{cm}^{-2}$. They are tested at specific currents of $0.1 \mathrm{Ag}^{-1}$ to $5 \mathrm{Ag}^{-1}$ at different temperatures. All samples exhibit a higher capacity at lower temperatures, confirming our previous observation (see Supplementary Fig. 14a-d for details). A high areal capacity of $2.1 \mathrm{mAh}$ $\mathrm{cm}^{-2}\left(0.1 \mathrm{~A} \mathrm{~g}^{-1}\right)$ at a mass loading of $4 \mathrm{mg} \mathrm{cm}^{-2}$ and $-20^{\circ} \mathrm{C}$ is achieved. Besides, we also assemble flexible quasi-solid $\mathrm{Zn} \| \mathrm{E}$ $\mathrm{Bi}_{2} \mathrm{Se}_{3}$ cells with electrodeposited $\mathrm{Zn}$ on carbon cloth as the anode (Supplementary Fig. 15), which can successfully power a wristwatch at low temperature. Considering high-voltage applications, we boost the $\mathrm{Zn} \| \mathrm{E}-\mathrm{Bi}_{2} \mathrm{Se}_{3}$ cell voltage to $3.3 \mathrm{~V}$ through a DC-DC boost converter with a transition efficiency of $90 \%$ (Supplementary Fig. 16a). We first charge $\mathrm{Zn} \| \mathrm{E}-\mathrm{Bi}_{2} \mathrm{Se}_{3}$ to $2.3 \mathrm{~V}$, then connect it to the converter following by discharging at $-20^{\circ} \mathrm{C}$. Even at $3.3 \mathrm{~V}$, considerable capacity of $438 \mathrm{mAh} \mathrm{cm}^{-3}\left(0.5 \mathrm{Ag}^{-1}\right)$, and $386 \mathrm{mAh} \mathrm{cm}^{-3}\left(1 \mathrm{Ag}^{-1}\right)$ are obtained, verifying the lowtemperature application potential. $\mathrm{Zn} \| \mathrm{E}-\mathrm{Bi}_{2} \mathrm{Se}_{3}$ exhibits a maximum specific energy of $441 \mathrm{Wh} \mathrm{kg}^{-1}$ at a specific power of $683 \mathrm{~W} \mathrm{~kg}^{-1}$, which is remarkable better than that of other reported aqueous AZIBs, especially at low temperature (Supplementary Fig. 16b).

The Zn-ion storage mechanistic study of $\mathrm{E}_{-} \mathrm{Bi}_{2} \mathrm{Se}_{3}$. Our findings clearly indicate that topological insulating states play a crucial role in the unique low-temperature performance of the $\mathrm{Zn} \| \mathrm{E}$ $\mathrm{Bi}_{2} \mathrm{Se}_{3}$ system. To reveal the mechanism underlying this performance, we first employed ex situ XRD to investigate the $\mathrm{E}-\mathrm{Bi}_{2} \mathrm{Se}_{3}$ cathode during charge and discharge. Figure $5 \mathrm{a}$ presents the XRD patterns of the $\mathrm{E}_{-} \mathrm{Bi}_{2} \mathrm{Se}_{3}$ cathode at selected charge/discharge states corresponding to the GCD profile at $0.3 \mathrm{~A} \mathrm{~g}^{-1}$ in the liquid electrolyte (see Supplementary Fig. 17 for electrochemical performance of the rechargeable $\mathrm{Zn} \| \mathrm{E}-\mathrm{Bi}_{2} \mathrm{Se}_{3}$ cells in $\left.1 \mathrm{~m} \mathrm{Zn(TFSI}\right)_{2}$ and $21 \mathrm{~m} \mathrm{LiTFSI} / \mathrm{H}_{2} \mathrm{O}$ aqueous electrolyte), and magnified XRD patterns of characteristic peaks are shown in Fig. 5b. During the discharge process (samples $1-8$ in the red region), three sets of peaks at $17.7^{\circ}, 24.7^{\circ}$, and $43.4^{\circ}$ [indexed to the (006), (101), and (110) planes of $\mathrm{Bi}_{2} \mathrm{Se}_{3}$ ] shift to lower angles, indicating that the intercalation of $\mathrm{Zn}^{2+}$ triggers expansion of the interlayer spacing. During subsequent charging of the cell to $2.3 \mathrm{~V}$ (samples 9-16 in the blue region), these peaks gradually migrate back to their initial positions, reflecting the highly reversible crystal structure evolution of $\mathrm{E}-\mathrm{Bi}_{2} \mathrm{Se}_{3}$. The peaks at approximately $29^{\circ}, 40^{\circ}$, and $53.2^{\circ}-$

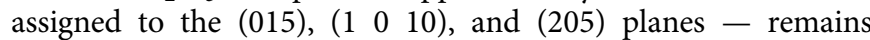
almost unchanged during the charge-discharge process (Supplementary Fig. 18). Ex situ Raman spectra are obtained to analyze the cathode's structural stability during the electrochemical process (Supplementary Fig. 19). The representative Raman-active modes of $\mathrm{Bi}_{2} \mathrm{Se}_{3}\left({ }^{1} A_{1 \mathrm{~g}},{ }^{2} E_{\mathrm{g}}\right.$, and ${ }^{2} A_{1 \mathrm{~g}}$ located at 72,132 , and $174 \mathrm{~cm}^{-1}$, respectively) are enlarged in Fig. $5 \mathrm{c}$. The corresponding measurements of intensity and full width at half maximum (FWHM) of Raman-active modes $\left({ }^{1} A_{1 \mathrm{~g}},{ }^{2} E_{\mathrm{g}}\right.$, and $\left.{ }^{2} A_{1 \mathrm{~g}}\right)$ in Supplementary Fig. $19 \mathrm{c}$ reveals that upon discharge to $0.1 \mathrm{~V}$, the three modes become broader and weaker, which corresponds to the embedding of $\mathrm{Zn}^{2+}$ into the interlayers of $\mathrm{E}_{-} \mathrm{Bi}_{2} \mathrm{Se}_{3}$. When charging to $2.3 \mathrm{~V}$, these characteristic peaks gradually become stronger and finally return to their initial states, which can be attributed to the deintercalation of $\mathrm{Zn}^{2+}$ from the electrode framework. The Raman results further rule out solvent insertion, confirming that $\mathrm{Zn}^{2+}$ is exclusively responsible for the enlarged spacing. TEM is conducted to probe the structural and mor-

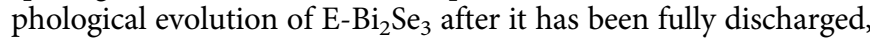
presenting the interlaced ultra-thin nanosheets (Fig. 5d). Under higher magnification in Fig. 5e with SAED patterns in Supplementary Fig. 20a, b, the high crystallinity of $\mathrm{E}_{-} \mathrm{Bi}_{2} \mathrm{Se}_{3}$ is accompanied by an increase in the interplanar spacing from 0.206 to $0.215 \mathrm{~nm}$, indexed to the (110) plane. Also, a characteristic superlattice pattern is observed in which a hexagon of six superlattice spots surrounds each of the host lattice spots as shown in Fig. $5 \mathrm{f}$ and Supplementary Fig. 20c. The experimental intensity of the spots and the interplanar spacing are analyzed to be 0.274 and $0.160 \mathrm{~nm}$ which corresponds to the (107) and (l) 2 10) planes of $\mathrm{Zn}_{x} \mathrm{Bi}_{2} \mathrm{Se}_{3}$, respectively. These planes are in good agreement with those of the simulated electron diffraction pattern of $\mathrm{Zn}_{4} \mathrm{Bi}_{2} \mathrm{Se}_{3}$ crystal taken along the same zone axis of [001] demonstrating the intercalated $\mathrm{Zn}^{2+}$ in the interlayer (Supplementary Fig. 20d). While there are no significant changes in the spacing of (018), (015), and (107) planes (Fig. 5g and Supplementary Fig. 21), which is in agreement with the XRD results. The HAADF-STEM image taken from a red dotted rectangular box in Supplementary Fig. 22a is shown in Fig. 5h. The layered structure of $\mathrm{Zn}_{x} \mathrm{Bi}_{2} \mathrm{Se}_{3}$ follows the layered $\mathrm{Zn}_{\mathrm{x}} \mathrm{Bi}_{2} \mathrm{Se}_{3}$ lattice (Supplementary Fig. 22b). Inset is an FFT pattern showing the (003) crystallographic plane. Figure $5 \mathrm{i}$ is a magnified view from a rectangular area from Fig. $5 \mathrm{~h}$. Bi atom is located in the middle position between two Se atoms (Supplementary Fig. $22 \mathrm{c}-\mathrm{f}$ ). Figure $5 \mathrm{j}$ shows an intensity profile from the magnified part of Fig. 5i. The $\mathrm{Zn}^{2+}$ occupies the position between the Se layers (quantification of the HAADF image is discussed in detail in Supplementary Fig. 22e, f. Comparison of the vertical line scan profiles of the HAADF images of $\mathrm{E}_{-} \mathrm{Bi}_{2} \mathrm{Se}_{3}$ and $\mathrm{ZnxBi}_{2} \mathrm{Se}_{3}$ is shown in Supplementary Fig. 22g. TEM-EDS elemental mappings (Fig. 5k) and corresponding TEM-EDS spectrum (Supplementary Fig. 23) reveal that $\mathrm{Zn}$ uniformly intercalates in the $\mathrm{E}-\mathrm{Bi}_{2} \mathrm{Se}_{3}$ nanosheets. The electrode remains in 

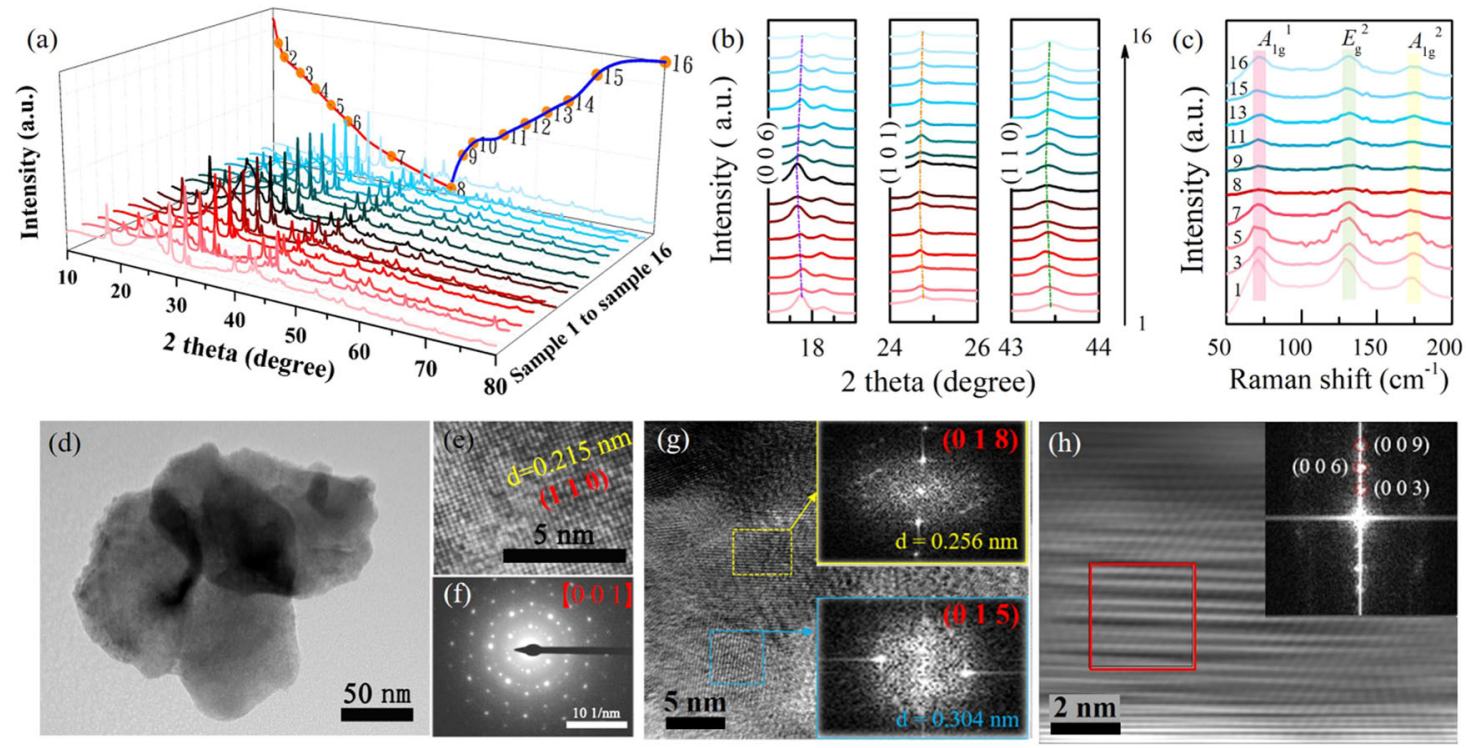
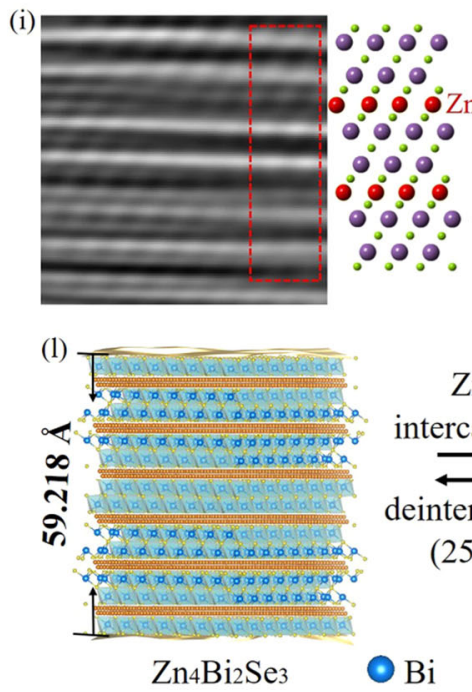

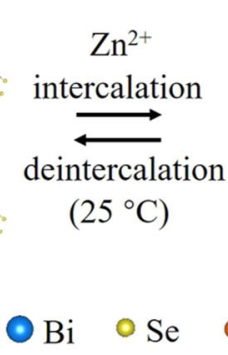

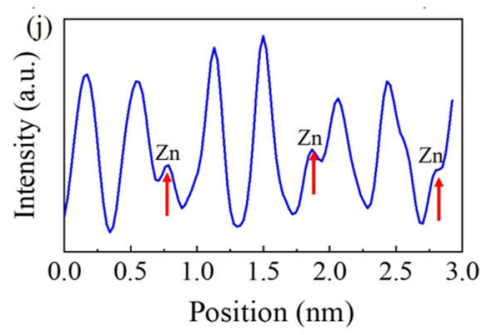

(k)
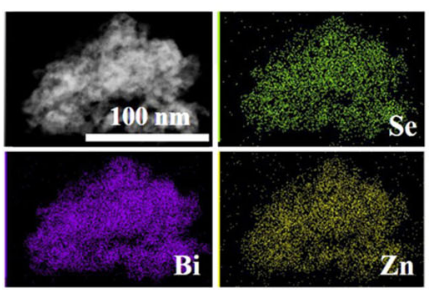

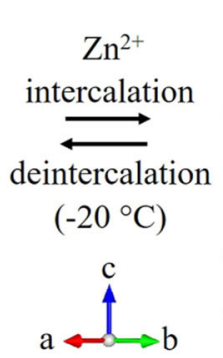

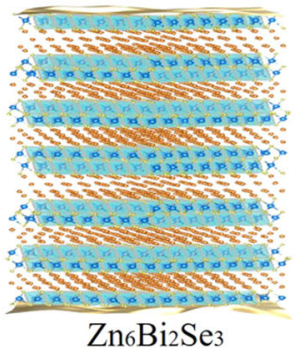

Fig. 5 Structural evolution of the $\mathbf{E}_{-} \mathbf{B i}_{\mathbf{2}} \mathbf{S e}_{\mathbf{3}}$ cathode during electrochemical cycling. a Evolution of ex situ XRD patterns during the charge/discharge process for $\mathrm{E}_{-} \mathrm{Bi}_{2} \mathrm{Se}_{3}$ for the third cycle in the liquid electrolyte at $0.3 \mathrm{~A} \mathrm{~g}^{-1}$ (the solid dots numbered sequentially from 1 to 16 refer to the positions at which the XRD patterns are obtained, and the red region is corresponding to the discharge process while the blue corresponding to the charge process).

b Magnified XRD patterns from a for $17^{\circ}-19^{\circ}, 24^{\circ}-26^{\circ}$, and $43^{\circ}-44^{\circ}$. c Magnified part $\left(50-200 \mathrm{~cm}^{-1}\right)$ of ex situ Raman spectra of the $\mathrm{E}_{-} \mathrm{Bi}_{2} \mathrm{Se}_{3}$ at the selected states corresponding to the charge/discharge process illustrated in a. d TEM image and e high-resolution TEM (HRTEM) image of E-Bi ${ }_{2} \mathrm{Se}_{3}$ at fully discharged state after three cycles. $\mathbf{f} \mathrm{SAED}$ pattern of $\mathrm{E}-\mathrm{Bi}_{2} \mathrm{Se}_{3}$ at fully discharged state. $\mathbf{g}$ HRTEM image of fully discharged $\mathrm{E}-\mathrm{Bi}_{2} \mathrm{Se}_{3}$ revealing (018) and (015) planes with insets displaying fast Fourier transform patterns. $\mathbf{h}$ HAADF-STEM image of $\mathrm{Zn}_{x} \mathrm{Bi}_{2} \mathrm{Se}_{3}$, and its corresponding FT pattern. $\mathbf{i}$ Magnified part from the red box in $\mathbf{h}$ with the $\mathrm{Zn}_{x} \mathrm{Bi}_{2} \mathrm{Se}_{3}$ crystal structure and $\mathbf{j}$ corresponding intensity profile. The red arrows in $\mathbf{j}$ indicate the presence and specific location of $\mathrm{Zn}^{2+}$ sites. $\mathbf{k}$ TEM-EDS elemental maps of $\mathrm{Bi}$, Se and $\mathrm{Zn}$ are given in colors of purple, green and yellow dots, respectively. I Schematic of $Z \mathrm{n}^{2+}$ intercalation and deintercalation in the $\mathrm{E}_{-} \mathrm{Bi}_{2} \mathrm{Se}_{3}$ cathode upon electrochemical charge and discharge process at -20 or $25^{\circ} \mathrm{C}$. Gold sequins represent topological surface states.

the original pattern of ultrathin interconnected nanosheets anchored stably on the base (see Supplementary Fig. 24 for different magnifications), and Supplementary Fig. 25 depicts the $\mathrm{Zn} 2 p$ corelevel spectra of the $\mathrm{E}-\mathrm{Bi}_{2} \mathrm{Se}_{3}$ cathode in three stages. In its original state, the spectrum doesn't manifest the $\mathrm{Zn} 2 p_{1 / 2}-2 p_{3 / 2}$ spin-orbit doublet, whereas the spectrum of the cathode discharged to $0.1 \mathrm{~V}$ confirms successful intercalation of $\mathrm{Zn}^{2+}$ (insertion state), and the weak signal in the spectrum obtained for the cathode on charge clearly reveals the retention of a few intercalated $\mathrm{Zn}^{2+}$ (extraction state), which offers clear evidence of reversible $\mathrm{Zn}^{2+}$ intercalation/ deintercalation into the $\mathrm{E}-\mathrm{Bi}_{2} \mathrm{Se}_{3}$ cathode.

To gain additional insights into the potential mechanism underlying the unique low-temperature electrochemical properties, we investigate the $\mathrm{Zn}^{2+}$ insertion model, electronic structures, and $\mathrm{Zn}^{2+}$ ion diffusion kinetics for $\mathrm{E}-\mathrm{Bi}_{2} \mathrm{Se}_{3}$ by using DFT calculations and $\mathrm{ab}$ initio $\mathrm{MD}$ simulation. A reversible crystal structure transformation between $\mathrm{E}_{-}-\mathrm{Bi}_{2} \mathrm{Se}_{3}$ and $\mathrm{Zn}_{x} \mathrm{Bi}_{2} \mathrm{Se}_{3}$ during the charge-discharge process is illustrated in Fig. 51. During the discharge process, the discharge capacity of $327 \mathrm{mAh} \mathrm{g}^{-1}$ under a specific current of $0.3 \mathrm{Ag}^{-1}$ at $25^{\circ} \mathrm{C}$ corresponds to the $\mathrm{Zn}$ insertion phase, with the stoichiometry of $\mathrm{Zn}_{4} \mathrm{Bi}_{2} \mathrm{Se}_{3}$ amounting to almost $99.88 \%$ of the calculated capacity $\left(327.4 \mathrm{mAh}^{-1}\right)$, and strikingly, the low-temperature $\left(-20^{\circ} \mathrm{C}\right)$ discharge capacity of $524 \mathrm{mAh} \mathrm{g}^{-1}$ at $0.3 \mathrm{~A} \mathrm{~g}^{-1}$ corresponds to $\mathrm{Zn}_{6} \mathrm{Bi}_{2} \mathrm{Se}_{3}$. After intercalation at $25^{\circ} \mathrm{C}$, the unit cell parameter $(c$, perpendicular to QLs) increases from 29.16 to $32.92 \AA\left(\mathrm{Zn}_{4} \mathrm{Bi}_{2} \mathrm{Se}_{3}\right)$. Upon the 

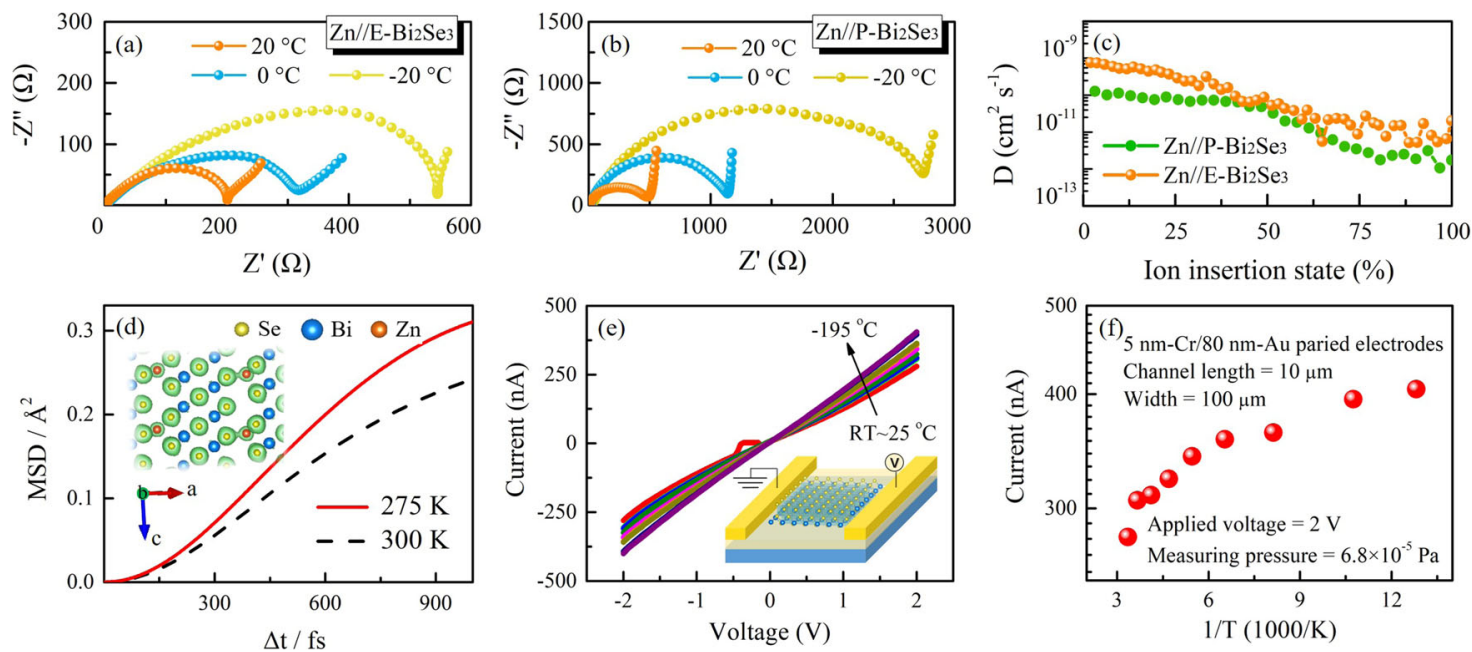

Fig. 6 Study of the low-temperature electronic conductivity and ion diffusion kinetics of $\mathrm{E}_{-}-\mathrm{Bi}_{2} \mathrm{Se}_{\mathbf{3}}$ cathode. $\mathrm{EIS}$ of the $\mathbf{a} \mathrm{Zn} \| \mathrm{E}-\mathrm{Bi}_{2} \mathrm{Se} \mathrm{e}_{3}$ and $\mathbf{b} \mathrm{Zn} \| \mathrm{P}-\mathrm{Bi}_{2} \mathrm{Se} \mathrm{e}_{3}$ cells, obtained at $-2 \mathrm{O}, 0$, and $20^{\circ} \mathrm{C}$. c Diffusivity coefficient (D) of $\mathrm{Zn}{ }^{2+}$, calculated using the GITT, of $\mathrm{Zn} \| \mathrm{E}-\mathrm{Bi}_{2} \mathrm{Se}_{3}$ and $\mathrm{Zn} \| \mathrm{P}-\mathrm{Bi}_{2} \mathrm{Se}_{3}$ cells in the third cycle at $25^{\circ} \mathrm{C}$. $\mathbf{d}$ MSD of the $\mathrm{Zn}$ between $4 \times 4 \times 1$ supercell $\mathrm{Bi}_{2} \mathrm{Se}_{3}$ bilayers, as discovered using ab initio MD simulation at 275 and $300 \mathrm{~K}$, respectively. The inset displays electron density plot for the $\mathrm{Zn}_{x} \mathrm{Bi}_{2} \mathrm{Se}_{3}$ skeleton. e l-V curves of $\mathrm{Zn}_{x} \mathrm{Bi}_{2} \mathrm{Se}_{3}$ with inset showing schematic of the $\mathrm{Zn}_{x} \mathrm{Bi}_{2} \mathrm{Se}_{3} \mathrm{nanosheet} \mathrm{ievice}$ fabricated for the electrical transport experiment and $\mathbf{f}$ the corresponding temperature-dependent current analysis on the $\mathrm{Zn}_{x} \mathrm{Bi}_{2} \mathrm{Se}_{3}$ device.

subsequent charge process, $\mathrm{Zn}^{2+}$ is reversibly deintercalated from $\mathrm{Zn}_{4} \mathrm{Bi}_{2} \mathrm{Se}_{3}$ and, together with two electrons, is transformed into the original Zn. Overall, Supplementary Fig. 26 depicts a schematic of the full rechargeable $\mathrm{Zn}|| \mathrm{E}-\mathrm{Bi}_{2} \mathrm{Se}_{3}$ cell.

Low-temperature electronic conductivity and ion diffusion kinetics study of $\mathbf{E}-\mathbf{B i}_{2} \mathbf{S e}_{3}$. Because the performance of the electrolyte is worse at low temperatures than that at room temperature, it is believed that the enhanced electrochemical performances of $\mathrm{Zn} \| \mathrm{E}-\mathrm{Bi}_{2} \mathrm{Se}_{3}$ cells is mainly contributed by improved electrode properties. We then investigate the electronic conductivity and ion diffusion kinetics of $\mathrm{E}_{-} \mathrm{Bi}_{2} \mathrm{Se}_{3}$ electrodes at different temperatures. The electrochemical impedance spectra (EIS) of $\mathrm{Zn} \| \mathrm{E}-\mathrm{Bi}_{2} \mathrm{Se}_{3}$ (Fig. 6a) and $\mathrm{Zn} \| \mathrm{P}-\mathrm{Bi}_{2} \mathrm{Se}_{3}$ cells (Fig. 6b) are conducted, and the fitting results with corresponding equivalent circuits are summarized in Supplementary Fig. 27. The $R_{\mathrm{i}}$ of $\mathrm{Zn} \|$ $\mathrm{E}-\mathrm{Bi}_{2} \mathrm{Se}_{3}$ is much smaller relative to that of $\mathrm{Zn} \| \mathrm{P}-\mathrm{Bi}_{2} \mathrm{Se}_{3}$, especially at $-20^{\circ} \mathrm{C}(252$ vs. $2320 \Omega)$, indicating the far better wettability of the $\mathrm{E}^{-} \mathrm{Bi}_{2} \mathrm{Se}_{3}$ electrode for the HC-EGPAM electrolyte, caused by the enlarged interlayer spacing. The slightly increased $R_{\mathrm{s}}$ of $\mathrm{Zn} \| \mathrm{E}-\mathrm{Bi}_{2} \mathrm{Se}_{3}$ from $6.2 \Omega$ at $20^{\circ} \mathrm{C}$ to $8.55 \Omega$ at $-20^{\circ} \mathrm{C}-$ which involves the resistance of the HC-EGPAM, separator, and $\mathrm{E}-\mathrm{Bi}_{2} \mathrm{Se}_{3}$ electrode-reflects the good electric conductivity of the cells. The faradic impedance (namely the combination of $R_{\mathrm{ct}}$ and $Z_{\mathrm{W}}$ ) reflects the kinetics of the cell reactions ${ }^{57}$. Herein, the considerably lower $R_{\mathrm{ct}}$ at $-20{ }^{\circ} \mathrm{C}(288 \Omega)$ of $\mathrm{Zn} \| \mathrm{E}-\mathrm{Bi}_{2} \mathrm{Se}_{3}$ than the $R_{\mathrm{ct}}$ of $\mathrm{Zn} \| \mathrm{P}-\mathrm{Bi}_{2} \mathrm{Se}_{3}(500 \Omega)$ favorably escorts fast $\mathrm{Zn}^{2+}$ diffusion kinetics. Additionally, $Z_{\mathrm{w}}$ is assigned to the $\mathrm{Zn}^{2+}$ diffusion in the cell $^{58}$. As the slope is proportional to $Z_{\mathrm{w}}$, the $\mathrm{Zn} \| \mathrm{E}-\mathrm{Bi}_{2} \mathrm{Se}_{3}$ cell with smaller slopes incidates a faster $\mathrm{Zn}^{2+}$ diffusion ${ }^{59}$. These results reveal that the stable ionic transport and higher electric conductivity of the $\mathrm{Zn} \| \mathrm{E}-\mathrm{Bi}_{2} \mathrm{Se}_{3}$ cell in cold environments far surpass those of the $\mathrm{Zn} \| \mathrm{P}-\mathrm{Bi}_{2} \mathrm{Se}_{3}$ cell.

In addition, the average $\mathrm{Zn}^{2+}$ diffusion coefficient of the $\mathrm{Zn} \| \mathrm{E}$ $\mathrm{Bi}_{2} \mathrm{Se}_{3}$ cell is calculated using the galvanostatic intermittence titration technique (GITT) to be $10^{-10}-10^{-11} \mathrm{~cm}^{2} \mathrm{~s}^{-1}$, higher than that of the $\mathrm{Zn} \| \mathrm{P}-\mathrm{Bi}_{2} \mathrm{Se}_{3}$ cell (Fig. $6 \mathrm{c}$ and Supplementary Fig. 28). To unravel the low-temperature $\mathrm{Zn}^{2+}$ diffusion of the $\mathrm{E}-\mathrm{Bi}_{2} \mathrm{Se}_{3}$ cathode, we calculate the mean square displacement (MSD) by selecting last 4000-steps in the simulation. Figure $6 \mathrm{~d}$ graphs the calculated MSD of the $\mathrm{Zn}$ ions between the bilayer
$\mathrm{E}-\mathrm{Bi}_{2} \mathrm{Se}_{3}$ at 275 and $300 \mathrm{~K}$. The MSD of $\mathrm{Zn}$ in $\mathrm{E}-\mathrm{Bi}_{2} \mathrm{Se}_{3}$ at $275 \mathrm{~K}$ is clearly higher than that at $300 \mathrm{~K}$. On the basis of the calculated MSD, we compute the diffusion coefficient of $\mathrm{Zn}$ ions within the bilayer $\mathrm{Bi}_{2} \mathrm{Se}_{3}$ at 275 and $300 \mathrm{~K}, 5.993 \times 10^{-5} \mathrm{~m}^{2} \mathrm{~s}^{-1}$ and $4.603 \times 10^{-5} \mathrm{~m}^{2} \mathrm{~s}^{-1}$, respectively, indicating that the $\mathrm{Zn}$ ions diffuse more quickly at the lower temperature $(275 \mathrm{~K})$ than the higher temperature $(300 \mathrm{~K})$ in the topological $\mathrm{E}-\mathrm{Bi}_{2} \mathrm{Se}_{3}$. This phenomenon can be attributed to the weaker lattice vibration of the $\mathrm{E}-\mathrm{Bi}_{2} \mathrm{Se}_{3}$ bilayer at $275 \mathrm{~K}$ than at $300 \mathrm{~K}$, which facilitates the movement of $\mathrm{Zn}^{2+}$. Additionally, the inset of Fig. $6 \mathrm{~d}$ shows an electron density plot for the $\mathrm{Zn}_{x} \mathrm{Bi}_{2} \mathrm{Se}_{3}$ skeleton, and Bader analysis reveals that some electrons from $\mathrm{Zn}$ are transferred to E- $\mathrm{Bi}_{2} \mathrm{Se}_{3}$ after $\mathrm{Zn}^{2+}$ intercalation into the $\mathrm{E}-\mathrm{Bi}_{2} \mathrm{Se}_{3}$ cathode. Consequently, the intercalated $\mathrm{Zn}^{2+}$ bears an effective charge of 1.89 (smaller than the nominal charge of 2), contributing to the ions' high mobility in $\mathrm{E}^{-} \mathrm{Bi}_{2} \mathrm{Se}_{3}{ }^{60}$.

To elaborate the temperature-dependent conductance characteristics of the topological electrode, several $\mathrm{E}-\mathrm{Bi}_{2} \mathrm{Se}_{3}$ and $\mathrm{Zn}_{x} \mathrm{Bi}_{2} \mathrm{Se}_{3}$ nanosheets, obtained by discharging the $\mathrm{E}-\mathrm{Bi}_{2} \mathrm{Se}_{3}$ cathode to $0.1 \mathrm{~V}$ at $0.3 \mathrm{Ag}^{-1}$, are separately configured for direct-current transport measurements by using standard electron beam lithography and thermal evaporation of $\mathrm{Cr} / \mathrm{Au}$ contacts as displayed in the inset of $I$ - $V$ curves of $\mathrm{Zn}_{x} \mathrm{Bi}_{2} \mathrm{Se}_{3}$ (Fig. 6e). The corresponding current versus $1000 / T$ plots over the temperature range -195 to $25^{\circ} \mathrm{C}$ for the $\mathrm{E}-\mathrm{Bi}_{2} \mathrm{Se}_{3}$ and $\mathrm{Zn}_{x} \mathrm{Bi}_{2} \mathrm{Se}_{3}$ devices are presented in Supplementary Fig. 29a and Fig. $6 \mathrm{f}$, respectively. The linear $I-V$ relationship proves that the ohmic-like contacts between the $\mathrm{Zn}_{x} \mathrm{Bi}_{2} \mathrm{Se}_{3}$ nanosheets and $\mathrm{Cr} / \mathrm{Au}$ electrodes ${ }^{61}$. Notably, the resistance of the as-prepared $\mathrm{E}-\mathrm{Bi}_{2} \mathrm{Se}_{3}$ nanosheets and discharging-product $\mathrm{Zn}_{x} \mathrm{Bi}_{2} \mathrm{Se}_{3}$ nanosheets decrease as the temperature declines from 25 to $-195^{\circ} \mathrm{C}$, in favorable agreement with the expected metallic behavior. Here, the effect of heavily doped properties of bulk defects is not ruled out. When the temperature drops, the current of the $\mathrm{Zn}_{x} \mathrm{Bi}_{2} \mathrm{Se}_{3}$ nanosheet device steadily rises, indicating a continued reduction in resistance; the decrease in resistance of $\mathrm{E}-\mathrm{Bi}_{2} \mathrm{Se}_{3}$ tends to saturation, and the resistance of $\mathrm{Zn}_{x} \mathrm{Bi}_{2} \mathrm{Se}_{3}$ is much lower than that of $\mathrm{E}-\mathrm{Bi}_{2} \mathrm{Se}_{3}$, demonstrating the metallic temperature dependence of both materials and prominently improved conductivity $\left(\sim 1.2-1.5\right.$ times) after $\mathrm{Zn}^{2+}$ embedding in $\mathrm{Zn}_{x} \mathrm{Bi}_{2} \mathrm{Se}_{3}$ nanosheets. 
(a)

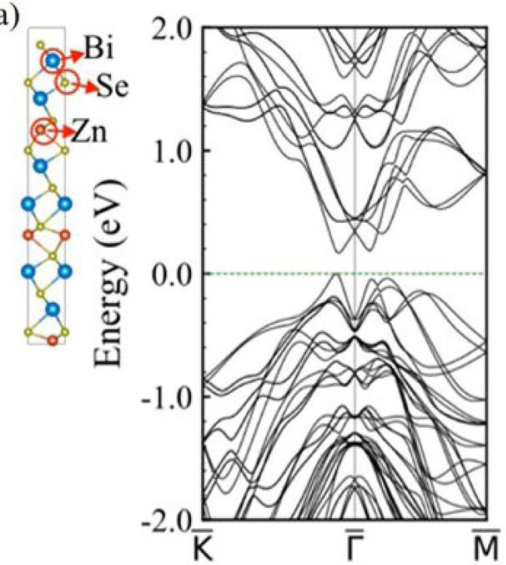

(c)

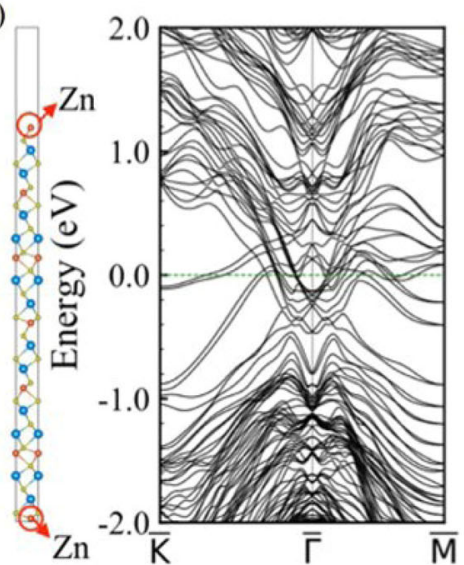

(b)

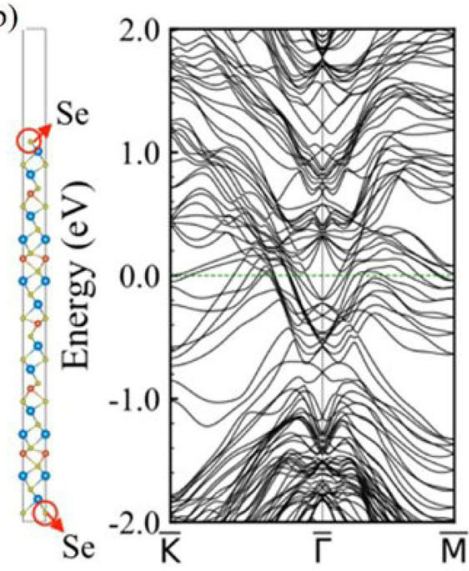

(d)

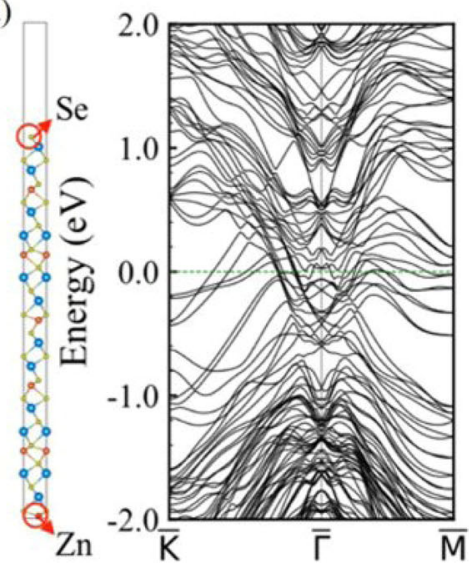

Fig. 7 Theoretical calculations of spin-orbit coupling (SOC) band structure of $\mathbf{Z n}^{2+}$ intercalated in $\mathbf{B i}_{2} \mathbf{S e}_{\mathbf{3}}$ interlayers. a Illustration of the supercell for modeling $\mathrm{Zn}^{2+}$ intercalated in $\mathrm{Bi}_{2} \mathrm{Se}_{3}$ interlayers (here denoted as $\mathrm{Zn}^{2+} \mathrm{Bi}_{2} \mathrm{Se}_{3}$ ) and the correspondent $\mathrm{SOC}$ band structure. $\mathbf{b}$-d $\mathrm{SOC}$ band structures of $\mathrm{Zn}^{2+} \mathrm{Bi}_{2} \mathrm{Se}_{3}$ 6-QL slab model with Se-Se (b), Zn-Zn (c), and Se-Zn (d) surface termination.

Spin-orbit coupling band structure calculation of $\mathrm{Zn}_{\mathrm{X}} \mathrm{Bi}_{2} \mathrm{Se}_{3}$. The information from the electronic structures of these materials is vital to multivalent chemistries ${ }^{62}$. Figure $7 \mathrm{a}$ shows the calculated spin-orbit coupling (SOC) band structure of $\mathrm{Zn}^{2+}$ intercalated in $\mathrm{Bi}_{2} \mathrm{Se}_{3}$ interlayers $\left(\mathrm{Zn}^{2+} \mathrm{Bi}_{2} \mathrm{Se}_{3}\right)$, which gives a band gap of $0.17 \mathrm{eV}$, illustrating the semiconducting nature in the bulk. The 6-QL slab models with different type of elements terminated at the top and bottom surface are employed to investigate the surface electronic structure of the nanosheet (Fig. 7b-d). For all the Se-Se, Zn-Zn, and Se-Zn terminated slabs, the band gap close and make the system metallic, and the band structures do not show any noticeable difference. Compared with the bulk band structure, the conduction bands shift downward and mix with the valence bands, indicating the existence of metallic surface states. In addition, because $\mathrm{Bi}_{2} \mathrm{Se}_{3}$ has the intrinsic topological surface states (Supplementary Figs. 29b and $30 \mathrm{a})$, even if the topological surface states still exist after $\mathrm{Zn}^{2+}$ incorporation, the number of bands will remain unchanged. The metallic surface states play a leading role in the material's conductivity. Due to the overlapping of the conduction and valence bands, it is difficult to distinguish the topological states even if the topological surface states of $\mathrm{Zn}^{2+} \mathrm{Bi}_{2} \mathrm{Se}_{3}$ are still retained. The neutral system with intercalated charge-neutral zinc atoms is also calculated for comparison (see Supplementary Fig. 30b-e for details), which implies the existence of topological surface states. It can be concluded that after $\mathrm{Zn}^{2+}$ intercalated into the $\mathrm{E}-\mathrm{Bi}_{2} \mathrm{Se}_{3}$ cathode, $\mathrm{Zn}^{2+}$ tends to be located around Se atoms on one side, elongating the Bi-Se bonds and resulting in an increased lattice parameter along the $c$ axis, as illustrated in Supplementary
Fig. 31. A bandgap exists in the bulk, and the results obtained through the calculation for the 6-QL slab model display surface metallicity; the conductivity of $\mathrm{Zn}_{\mathrm{x}} \mathrm{Bi}_{2} \mathrm{Se}_{3}$ benefits from metallic surface states, as proposed in the schematic plot of Supplementary Fig. 32.

The dominant mechanisms responsible for the abnormal lowtemperature $\mathrm{Zn}$ storage performance of $\mathrm{Zn} \| \mathrm{E}-\mathrm{Bi}_{2} \mathrm{Se}_{3}$ can be briefly summarized as follows: the surface metallic feature and topological protection result in enhanced electrical conductivity of $\mathrm{E}_{-} \mathrm{Bi}_{2} \mathrm{Se}_{3}$ at low temperatures. In addition, weak lattice vibration of the $\mathrm{E}-\mathrm{Bi}_{2} \mathrm{Se}_{3}$ bilayer at low temperature results in rapid $\mathrm{Zn}^{2+}$ diffusion. The highlights of the previous discussion are that electronic and ionic conductivities are improved at low temperatures, accelerating $\mathrm{Zn}^{2+}$ (de)intercalation reactions. Additionally, the decent ionic conductivity of the anti-freeze HC-EGPAM electrolyte also contributes to the enhanced performance. It should be noted that while HC-EGPAM provide a good platform to study the unique features of the topological insulating $\mathrm{E}-\mathrm{Bi}_{2} \mathrm{Se}_{3}$ electrode, the high concentration of LiTFSI $(21 \mathrm{~m})$ in the electrolytes will inevitably increase the cost of the cell. Alternatives can be developed in future to address this problem ${ }^{63,64}$. The surface metallic feature and topological protection result in enhanced electrical conductivity open a venue for low temperature cells to achieve enhanced performances. Other materials such as topological semimetals with high electrical conductivity and suitable carrier density near Fermi level are enticing candidate materials for low-temperature electrochemical energy storage meriting from their topologically protected surface states. 


\section{Discussion}

All cell systems suffer from performance loss or failure at low temperatures, which is a long-standing problem. Herein, we demonstrate a low-temperature cell based on a few-layer $\mathrm{Bi}_{2} \mathrm{Se}_{3}$ topological insulator cathode, $\mathrm{Zn}$ anode, and HC-EGPAM electrolyte. The dependence of cell capacity on temperature is unusual-the lower the temperature is, the better the cell performance is. This is different from all previously reported low-temperature cells. The $\mathrm{Zn} \| \mathrm{E}-\mathrm{Bi}_{2} \mathrm{Se}_{3}$ cell delivers remarkable capacities of $327 \mathrm{mAh} \mathrm{g}$ $\left(25^{\circ} \mathrm{C}\right)$ and $524 \mathrm{mAh} \mathrm{g}^{-1}\left(-20^{\circ} \mathrm{C}\right)$ at $0.3 \mathrm{~A} \mathrm{~g}^{-1}$, and decent cycling performance, with $94.6 \%$ of its capacity retained over 2000 cycles at $0{ }^{\circ} \mathrm{C}$ and a $\mathrm{CE}$ approaching $100 \%$. The mechanism underlying the unusual temperature-dependent cell performance is interpreted by cooperatively utilizing experimental and theoretical strategies. It is revealed that, at a lower temperature, $\mathrm{E}-\mathrm{Bi}_{2} \mathrm{Se}_{3}$ realizes higher electrical conductivity, which is ascribed to a coupling advantage in the topological surface states. In addition, more rapid $\mathrm{Zn}$ ion diffusion in the $\mathrm{E}-\mathrm{Bi}_{2} \mathrm{Se}_{3}$ is observed and is attributed to weaker lattice vibration of the $\mathrm{E}_{-} \mathrm{Bi}_{2} \mathrm{Se}_{3}$ bilayer at lower temperature. In particular, the discharging-product $\mathrm{Zn}_{x} \mathrm{Bi}_{2} \mathrm{Se}_{3}$ exhibits higher conductivity than $\mathrm{E}-\mathrm{Bi}_{2} \mathrm{Se}_{3}$, taking advantage of reinforced trivial metallic surface states because of much-enlarged interlayer spacing and structure distortion after $\mathrm{Zn}^{2+}$ intercalation. These aspects, together with the prominent anti-freeze capability of the developed HC-EGPAM electrolyte, result in better cell performance at lower temperatures. Our study indicates that use of a topological insulator as an electrochemical electrode may result in substantially enhanced low-temperature cell performances, even better than that at room temperature. The developed cells can be an excellent choice for powering systems that operate in cold areas for long periods. Undoubtedly, this research will inspire research on low-temperature cells from the perspective of using a topological insulator as an electrode.

\section{Methods \\ Preparation of anti-freeze hydrogel electrolyte with high concentration of salts and ethylene glycol (HC-EGPAM). $\mathrm{Zn}(\mathrm{TFSI})_{2}$ (99\% purity) and LiTFSI (99\% purity) are purchased from Macklin reagent Co., LTD. The salts are used as received without further purification. A high concentration salt electrolyte is pre- pared by adding $1 \mathrm{~m} \mathrm{Zn(TFSI)})_{2}$ and $21 \mathrm{~m} \mathrm{LiTFSI} \mathrm{[where} \mathrm{m}$ is molality ( $\mathrm{mol} \mathrm{kg}^{-1}$ ) and TFSI denotes bis(trifluoromethanesulfonyl)imide] to $2 \mathrm{~mL}$ of deionized water under vigorous stirring at room temperature for $30 \mathrm{~min}$. After the salts are fully dissolved in the water, $2 \mathrm{~mL}$ of ethylene glycol (EG) antifreeze is mixed in. Acry- lamide, used as the monomer, $0.05 \mathrm{~g}$ of ammonium persulfate, used as the initiator, and $0.005 \times g$ of bisacrylamide, used as the crosslinker, are added together and stirred until a transparent dispersion is obtained. EG ( $99.5 \%$ purity), acrylamide ( $99 \%$ purity), ammonium persulfate ( $99 \%$ purity), and bisacrylamide ( $99 \%$ purity) are purchased from Macklin reagent Co., LTD and used as received. Subsequently, free-radical polymerization proceeds in an oil bath at $70{ }^{\circ} \mathrm{C}$ for $3 \mathrm{~h}$. For compar- ison, the polyacrylamide-based hydrogel electrolyte (HC-PAM) is prepared by replacing the EG additive with an equal amount of deionized water in the afore- mentioned process. $70 \% \mathrm{EG} /$ water has the lowest freezing point of $-55^{\circ} \mathrm{C}$. In our highly concentrated salts system, EG content can be up to $50 \%$.}

Synthesis of few-layer $\mathbf{B i}_{2} \mathrm{Se}_{\mathbf{3}}$ nanosheets $\left(\mathbf{E}-\mathrm{Bi}_{\mathbf{2}} \mathrm{Se}_{\mathbf{3}}\right) . \mathrm{E}-\mathrm{Bi}_{2} \mathrm{Se}_{3}$ nanosheets are readily fabricated using a facile two-step high-energy mechanical milling (HEMM)/ lithium intercalation approach, and $\mathrm{Bi}_{2} \mathrm{Se}_{3}$ powder $\left(\mathrm{P}-\mathrm{Bi}_{2} \mathrm{Se}_{3}\right)$ obtained through HEMM can be easily exfoliated into a stable suspension by using the hydration force (Supplementary Fig. 1). High-purity bismuth shot (Bi, 99.999\%; Alfa Aesar) and selenium shot (Se, 99.999\%; Alfa Aesar), weighed according to the stoichiometric ratio of $\mathrm{Bi}_{2} \mathrm{Se}_{3}$ are loaded into a stainless-steel ball-milling jar in a glove box at room temperature under argon atmosphere $\left(<1 \mathrm{ppm}\right.$ of $\mathrm{H}_{2} \mathrm{O}$ and $\left.\mathrm{O}_{2}\right)$. The jar is subjected to ball milling for $20 \mathrm{~h}$ at $1200 \mathrm{rpm}$. Afterward, $150 \mathrm{mg}$ of ball-milled powder is added to a $70-\mathrm{mL}$ EG solution of lithium hydroxide $\left(8 \mathrm{~g} \mathrm{~L}^{-1}\right)$ under continuous stirring for $30 \mathrm{~min}$, after which the mixture is placed into a $100-\mathrm{mL}$ Teflon-lined autoclave. The autoclave is heated at $200^{\circ} \mathrm{C}$ for $28 \mathrm{~h}$ to obtain the fully exfoliated $\mathrm{Bi}_{2} \mathrm{Se}_{3}$ by plating/stripping $\mathrm{Li}^{+}$dispersed in the solution. The dispersion is centrifuged and then washed thoroughly using acetone (the amount of volume used is $250 \mathrm{~mL}$ ) and deionized water $(300 \mathrm{~mL})$ six times. Lithium hydroxide $(99.7 \%$ purity) and acetone ( $>99.5 \%$ purity) are purchased from Macklin reagent Co., LTD and used as received. A small amount of $\mathrm{SeO}_{2}$ impurity introduced during the HEMM process can be removed after washing with the tetramethylammonium hydroxide (TMAH, $0.023 \mathrm{M}) / \mathrm{NaOH}(0.006 \mathrm{M}) / \mathrm{NaCl}(0.016 \mathrm{M})$ aqueous solution and deionized water (Supplementary Fig. 7) ${ }^{30}$. TMAH (25 wt.\% in $\mathrm{H}_{2} \mathrm{O}$ ), $\mathrm{NaOH}$ $\left(68 \mathrm{~g} / \mathrm{L}\right.$ in $\left.\mathrm{H}_{2} \mathrm{O}\right)$ and $\mathrm{NaCl}(>99.5 \%$ purity) are purchased from Macklin reagent Co., LTD and used as received. After vacuum filtering through porous polyvinylidene fluoride (PVDF) membranes of $0.45-\mathrm{mm}$ nominal pore size, the resulting samples are dried in vacuum at $40{ }^{\circ} \mathrm{C}$ overnight.

Fabrication and electrochemical characterization of the quasi-solid $\mathrm{Zn} \mid$ | E$\mathbf{B i}_{\mathbf{2}} \mathbf{S e}_{\mathbf{3}}$ cell. To prepare the cathode, $\mathrm{E}-\mathrm{Bi}_{2} \mathrm{Se}_{3}$, acetylene black $(>99.99 \%$ purity, Macklin reagent), and PVDF adhesive (Solvay 5130 with a purity $>99.5 \%$, Solvay Specialty Polymers) are mixed uniformly in a 7:2:1 weight ratio with $N$-methyl2pyrrolidone (NMP, AR, Aladdin Reagent); then, the slurry is cast on a carbon cloth with a thickness of $1 \mathrm{~mm}$ (WOS 1009, Cetech Co., LTD), which is then vacuum dried. The areal loading of $\mathrm{E}_{-} \mathrm{Bi}_{2} \mathrm{Se}_{3}$ is approximately $1.6 \mathrm{mg} \mathrm{cm}^{-2}$. Electrodeposited $\mathrm{Zn}$ on carbon cloth (in flexible cells for demonstration) or $\mathrm{Zn}$ foil with purity of $99.99 \%$ and thickness of $0.15 \mathrm{~mm}$ purchased from Shanghai Ailiai Metallic Material Co., LTD (in CR2032 coin-type cells to evaluate the electrochemical properties) is used as an anode. The coin cell is crimped with a pressure of $5 \mathrm{MPa}$. The quasi-solid $\mathrm{Zn} \| \mathrm{E}-\mathrm{Bi}_{2} \mathrm{Se}_{3}$ cell is assembled by sandwiching HC-EGPAM between the $\mathrm{Zn}$ anode and $\mathrm{E}-\mathrm{Bi}_{2} \mathrm{Se}_{3}$ cathode CVs and EIS are obtained using a CHI 760E workstation. EIS is conducted at a quasistationary potential with two-electrode system in the frequency range from $1 \mathrm{MHz}$ to $0.1 \mathrm{~Hz}$ at open-circuit voltage, $5 \mathrm{mV}$ amplitude. The recording number of data points is 12 per decade. GCD profiles, rate capability, and cycling performance are determined using the LAND testing system. In order to avoid the influence of cell activation, the order of measurement of temperature-dependent rate ability is inititated from a small specific current of $0.3 \mathrm{Ag}^{-1}$ to a large specific current of $5 \mathrm{Ag}^{-1}$. The test begins after the completion of activation at $0.3 \mathrm{Ag}^{-1}$ at $25^{\circ} \mathrm{C}$ (around three cycles). The ionic conductivity $(\sigma)$ of the hydrogels can be calculated from alternatingcurrent impedance spectra obtained using two stainless-steel planar electrodes sandwiching the hydrogels. Then, $\sigma$ is calculated as a function of the ohmic resistance ( $R$; namely the $\mathrm{X}$-axis intercept of the profile), thickness $(l)$, and test area of the hydrogel $(A)$ through the following equation:

$$
\sigma=\frac{l}{R A}
$$

Material characterization. XRD data are collected using a Bruker D2 Phaser diffractometer and $\mathrm{Cu}-\mathrm{K} \alpha$ radiation $(\lambda=0.154 \mathrm{~nm})$. XRD refinement is performed using the GSAS-EXPGUI program. The morphology of the electrodes is examined using TEM (JEOL-2001F) and field-emission SEM (FEI/Philips XL30). Inductively coupled plasma-atomic emission spectroscopy (ICP-AES) is performed using the PerkinElmer Optima 8300. Raman spectroscopy is conducted using a multichannel modular triple Raman system (WITec alpha300 access). Chemical state and composition are analyzed using XPS (ESCALAB 250 photoelectron spectroscopy). For ex situ measurements of the cathode, batteries are firstly charged/discharged up to the specific potential using a LAND workstation. At the end of charged/discharge, these batteries are opened in the air to collect cathodes. Afterward, these cathodes are washed with deionized water three times. Finally, cathodes are dried in an oven at $60^{\circ} \mathrm{C}$ for 20 min for further ex situ measurements. For electrical transport experiments on the as-fabricated $\mathrm{E}_{-} \mathrm{Bi}_{2} \mathrm{Se}_{3}$ and discharging-product $\mathrm{Zn}_{x} \mathrm{Bi}_{2} \mathrm{Se}_{3}$, shadow masking is used to define the drain and source regions. $\mathrm{Cr} / \mathrm{Au}$ film electrodes of thickness $5 / 80 \mathrm{~nm}$ are deposited using electron beam evaporation. The channel lengths are $10 \mu \mathrm{m}$ for all devices. The devices are characterized using a standard electrical probe station and Agilent 4155C semiconductor analyzer in an ambient atmosphere. The low temperature test is done in ESPEC high and low temperature test chamber (GPS-3).

Calculation. The DFT calculations are performed using the Vienna ab initio simulation package (VASP) ${ }^{61}$ with the Perdew-Burke-Ernzerhof-type generalized gradient approximation (GGA-PBE) ${ }^{65}$. The electron-ion interaction is described by projected augmented wave (PAW) method ${ }^{66}$. The cutoff energy for the plane-wave basis sets is set to be $350 \mathrm{eV}$. The spin-orbit coupling (SOC) is taken into account due to the strong relativistic effect in Bi element. A slab model contained 6-QLs with a vacuum region of more than $15 \AA$ is used to model the $\mathrm{E}-\mathrm{Bi}_{2} \mathrm{Se}_{3}$ nanosheets. The Brillouin zone is sampled by a $12 \times 12 \times 2$ and $12 \times 12 \times 1 \Gamma$-centered $k$-mesh for bulk and slab model, respectively. All structures are completely relaxed until the residual force on each atom is $<0.01 \mathrm{eV} / \AA$. The Grimme's DFT-D3 method is used to describe the van der Waals interactions ${ }^{67}$. In order to simulate the $\mathrm{Zn}^{2+}$ diffusion process in the $\mathrm{E}-\mathrm{Bi}_{2} \mathrm{Se}_{3}$ interlayers, we perform the ab initio $\mathrm{MD}$ (AIMD) simulations using the Nosé algorithm ${ }^{68}$, with a time step of $2 \mathrm{fs}$ and a simulation period of 10 ps. A $4 \times 4 \times 1$ supercell containing 161 atoms and a $k$-point sampling at $\Gamma$-point is used in the AIMD.

Reporting summary. Further information on research design is available in the Nature Research Reporting Summary linked to this article.

\section{Data availability}

The data that support the findings of this study are available within the text including the Methods, and Supplemental information. Raw datasets related to the current work are available from the corresponding author on reasonable request. 
Received: 14 March 2021; Accepted: 19 January 2022;

Published online: 08 February 2022

\section{References}

1. Armand, M. \& Tarascon, J. M. Building better batteries. Nature 451, 652-657 (2008).

2. Goodenough, J. B. Rechargeable batteries: challenges old and new. J. Solid State Electrochem. 16, 2019-2029 (2012).

3. Jung, $\mathrm{H}$. G. et al. A high-rate long-life $\mathrm{Li}_{4} \mathrm{Ti}_{5} \mathrm{O}_{12} / \mathrm{Li}^{2}\left[\mathrm{Ni}_{0.45} \mathrm{Co}_{0.1} \mathrm{Mn}_{1.45}\right] \mathrm{O}_{4}$ lithium-ion battery. Nat. Commun. 2, 516 (2011).

4. Jaguemont, J. et al. A comprehensive review of lithium-ion batteries used in hybrid and electric vehicles at cold temperatures. Appl. Energy 164, 99-114 (2016).

5. You, Y. et al. Subzero-temperature cathode for a sodium-ion battery. $A d v$. Mater. 28, 7243-7248 (2016).

6. Mo, F. et al. A flexible rechargeable aqueous zinc manganese-dioxide battery working at $-20^{\circ} \mathrm{C}$. Energy Environ. Sci. 12, 706-715 (2019).

7. Sun, Z. et al. Grafting benzenediazonium tetrafluoroborate onto $\mathrm{LiNi}_{\mathrm{x}} \mathrm{Co}_{\mathrm{y}} \mathrm{Mn}_{\mathrm{z}} \mathrm{O}_{2}$ materials achieves subzero-temperature high-capacity lithium-ion storage via a diazonium soft-chemistry method. Adv. Energy Mater. 9, 1802946 (2018).

8. Zhao, Y. et al. Inhibiting grain pulverization and sulfur dissolution of bismuth sulfide by ionic liquid enhanced poly(3,4-ethylenedioxythiophene): poly(styrenesulfonate) for high-performance zinc-ion batteries. ACS Nano 13, 7270-7280 (2019).

9. Zhang, Y. et al. Enhanced rate capability and low-temperature performance of $\mathrm{Li}_{4} \mathrm{Ti}_{5} \mathrm{O}_{12}$ anode material by facile surface fluorination. ACS Appl. Mater. Interfaces 9, 17145-17154 (2017).

10. Luo, D. et al. Low-concentration donor-doped $\mathrm{LiCoO}_{2}$ as a high performance cathode material for Li-ion batteries to operate between -10.4 and $45.4^{\circ} \mathrm{C}$. J. Mater. Chem. 22, 22233-22241 (2012).

11. Moore, J. E. The birth of topological insulators. Nature 464, 194-198 (2010).

12. Hsieh, D. et al. A topological Dirac insulator in a quantum spin Hall phase. Nature 452, 970-974 (2008).

13. Peng, $\mathrm{H}$. et al. Aharonov-Bohm interference in topological insulator nanoribbons. Nat. Mater. 9, 225-229 (2010).

14. Nia, J. et al. Bismuth chalcogenide compounds $\mathrm{Bi}_{2} \mathrm{X}_{3}(\mathrm{X}=\mathrm{O}, \mathrm{S}, \mathrm{Se})$ : Applications in electrochemical energy storage. Nano Energy 34, 356-366 (2017).

15. Mishra, S. K. et al. Electronic structure and thermoelectric properties of bismuth telluride and bismuth selenide. J. Phys. Condens. Matter 9, 461-470 (1997).

16. Hong, S. S. et al. Ultrathin topological insulator $\mathrm{Bi}_{2} \mathrm{Se}_{3}$ nanoribbons exfoliated by atomic force microscopy. Nano Lett. 10, 3118-3122 (2010).

17. Moore, J. E. The next generation. Nat. Phys. 5, 378-380 (2009).

18. Xia, Y. et al. Observation of a large-gap topological-insulator class with a single Dirac cone on the surface. Nat. Phys. 5, 398-402 (2009).

19. Zhang, $\mathrm{H}$. et al. Topological insulators in $\mathrm{Bi}_{2} \mathrm{Se}_{3}, \mathrm{Bi}_{2} \mathrm{Te}_{3}$ and $\mathrm{Sb}_{2} \mathrm{Te}_{3}$ with a single Dirac cone on the surface. Nat. Phys. 5, 438-442 (2009).

20. Hsieh, D. et al. A tunable topological insulator in the spin helical Dirac transport regime. Nature 460, 1101-1105 (2009).

21. Yashina, L. V. et al. Negligible surface reactivity of topological insulators $\mathrm{Bi}_{2} \mathrm{Se}_{3}$ and $\mathrm{Bi}_{2} \mathrm{Te}_{3}$ towards oxygen and water. ACS Nano 7, 5181-5191 (2013).

22. Chen, C. et al. Robustness of topological order and formation of quantum well states in topological insulators exposed to ambient environment. Proc. Natl Acad. Sci. USA 109, 3694-3698 (2012).

23. Koski, K. J. et al. High-density chemical intercalation of zero-valent copper into $\mathrm{Bi}_{2} \mathrm{Se}_{3}$ nanoribbons. J. Am. Chem. Soc. 134, 7584-7587 (2012).

24. Chen, K. P. et al. Dual element intercalation into $2 \mathrm{D}$ layered $\mathrm{Bi}_{2} \mathrm{Se}_{3}$ nanoribbons. J. Am. Chem. Soc. 137, 5431-5437 (2015).

25. de la Mata, M. et al. Polarity assignment in ZnTe, GaAs, ZnO, and GaN-AlN nanowires from direct dumbbell analysis. Nano Lett. 12, 2579-2586 (2012).

26. Zhou, W. et al. Identification of active $\mathrm{Zr}-\mathrm{WO}_{\mathrm{x}}$ clusters on a $\mathrm{ZrO}_{2}$ support for solid acid catalysts. Nat. Chem. 1, 722-728 (2009).

27. Kong, D. et al. Rapid surface oxidation as a source of surface degradation factor for $\mathrm{Bi}_{2} \mathrm{Se}_{3}$. ACS Nano 5, 4698-4703 (2011).

28. Hobbs, R. G. et al. Resist-substrate interface tailoring for generating highdensity arrays of $\mathrm{Ge}$ and $\mathrm{Bi}_{2} \mathrm{Se}_{3}$ nanowires by electron beam lithography. $J$. Vac. Sci. Technol. B 30, 041602 (2012).

29. Hou, Y. B. et al. $\mathrm{Bi}_{2} \mathrm{Se}_{3}$ nanosheets: advanced nanofillers for reinforcing and flame retarding polyethylene nanocomposites. Compos. Part A Appl. Sci. Manuf. 100, 371-380 (2017).

30. Sobolev, V. V., Shutov, S. D., Popov, Yu. V. \& Shestatskii, S. N. et al. Reflectivity spectra of the rhombohedral crystals $\mathrm{Bi}_{2} \mathrm{Te}_{3}, \mathrm{Bi}_{2} \mathrm{Se}_{3}$, and $\mathrm{Sb}_{2} \mathrm{Te}_{3}$ over the Range from 0.7 to 12.5 eV. Phys. Status Solidi 30, 349-355 (1968).
31. Aurbach, D. et al. Review of selected electrode-solution interactions which determine the performance of $\mathrm{Li}$ and $\mathrm{Li}$ ion batteries. J. Power Sources 89, 206-218 (2000).

32. Guo, J. Z. et al. High-energy/power and low-temperature cathode for sodiumion batteries: in situ XRD study and superior full-cell performance. Adv. Mater. 29, 1701968 (2017).

33. $\mathrm{Xu}, \mathrm{H}$. et al. Hierarchical $\mathrm{Bi}_{2} \mathrm{Se}_{3}$ microrods: microwave-assisted synthesis, growth mechanism and their related properties. CrystEngComm 15, 1618-1625 (2013)

34. Hong, M. et al. Enhanced thermoelectric performance of ultrathin $\mathrm{Bi}_{2} \mathrm{Se}_{3}$ nanosheets through thickness control. Adv. Electron. Mater. 1, 1500025 (2015).

35. Kundu, D. et al. Organic cathode for aqueous zn-ion batteries: taming a unique phase evolution toward stable electrochemical cycling. Chem. Mater 30, 3874-3881 (2018).

36. Liu, C. et al. Expanded hydrated vanadate for high-performance aqueous zincion batteries. Energy Environ. Sci. 12, 2273-2285 (2019).

37. Ding, M. S. et al. Conductivity, viscosity, and their correlation of a superconcentrated aqueous electrolyte. J. Phys. Chem. C 121, 2149-2153 (2017)

38. Rui, L. et al. Counter-intuitive structural instability aroused by transition metal migration in polyanionic sodium ion host. Adv. Energy Mater. 11, 2003256 (2021)

39. Liang, Y. et al. Universal quinone electrodes for long cycle life aqueous rechargeable batteries. Nat. Mater. 16, 841-848 (2017).

40. Wu, X. et al. Carbon-nanotube-decorated nano-LiFePO $@$ @ cathode material with superior high-rate and low-temperature performances for lithium-ion batteries. Adv. Energy Mater. 3, 1155-1160 (2013).

41. Elia, G. A. et al. Nanostructured tin-carbon/LiNi ${ }_{0.5} \mathrm{Mn}_{1.5} \mathrm{O}_{4}$ lithium-ion battery operating at low temperature. J. Power Sources 275, 227-233 (2015).

42. Zhang, N. et al. Cation-deficient spinel $\mathrm{ZnMn}_{2} \mathrm{O}_{4}$ cathode in $\mathrm{Zn}\left(\mathrm{CF}_{3} \mathrm{SO}_{3}\right)_{2}$ electrolyte for rechargeable aqueous Zn-ion battery. J. Am. Chem. Soc. 138, 12894-12901 (2016).

43. Pan, $\mathrm{H}$. et al. Reversible aqueous zinc/manganese oxide energy storage from conversion reactions. Nat. Energy 1, 16039 (2016).

44. Xia, C. et al. Rechargeable aqueous zinc-ion battery based on porous framework zinc pyrovanadate intercalation cathode. Adv. Mater. 30, 1705580 (2018).

45. He, P. et al. Layered $\mathrm{VS}_{2}$ Nanosheet-based aqueous $\mathrm{Zn}$ ion battery cathode. Adv. Energy Mater. 7, 201601920 (2017).

46. Kundu, D. et al. A high-capacity and long-life aqueous rechargeable zinc battery using a metal oxide intercalation cathode. Nat. Energy 1, 119 (2016)

47. Yang, $\mathrm{Y}$. et al. $\mathrm{Li}^{+}$intercalated $\mathrm{V}_{2} \mathrm{O}_{5} \cdot \mathrm{nH}_{2} \mathrm{O}$ with enlarged layer spacing and fast ion diffusion as an aqueous zinc-ion battery cathode. Energy Environ. Sci. 11, 3157-3162 (2018).

48. Pang, Q. et al. $\mathrm{H}_{2} \mathrm{~V}_{3} \mathrm{O}_{8}$ Nanowire/graphene electrodes for aqueous rechargeable Zinc ion batteries with high rate capability and large capacity. Adv. Energy Mater. 8, 1800144 (2018)

49. Liu, J. et al. A flexible quasi-solid-state nickel-zinc battery with high energy and power densities based on 3D electrode design. Adv. Mater. 28, 8732-8739 (2016).

50. Zeng, Y. et al. Oxygen-vacancy and surface modulation of ultrathin nickel cobaltite nanosheets as a high-energy cathode for advanced $\mathrm{Zn}$-ion batteries. Adv. Mater. 30, 1802396 (2018).

51. Zhang, L. et al. Towards high-voltage aqueous metal-ion batteries beyond 1.5 V: the zinc/zinc hexacyanoferrate system. Adv. Energy Mater. 5, 1400930 (2015).

52. Yang, Q. et al. Activating C-coordinated iron of iron hexacyanoferrate for $\mathrm{Zn}$ hybrid-ion batteries with 10000 -cycle lifespan and superior rate capability. Adv. Mater. 31, 1901521 (2019).

53. Huang, J. et al. Polyaniline-intercalated manganese dioxide nanolayers as a high-performance cathode material for an aqueous zinc-ion battery. Nat Commun. 9, 2906 (2018).

54. Ji, X. et al. A highly ordered nanostructured carbon-sulphur cathode for lithium-sulphur batteries. Nat. Mater. 8, 500-506 (2009).

55. Li, H. et al. $\mathrm{MoS}_{2}$ nanosheets with expanded interlayer spacing for rechargeable aqueous Zn-ion batteries. Energy Storage Mater. 19, 94-101 (2018).

56. Ma, L. et al. Initiating a mild aqueous electrolyte $\mathrm{Co}_{3} \mathrm{O}_{4} / \mathrm{Zn}$ battery with 2.2 V-high voltage and 5000-cycle lifespan by a Co(iii) rich-electrode. Energy Environ. Sci. 11, 2521-2530 (2018).

57. Zhang, S. S. et al. Electrochemical impedance study on the low temperature of Li-ion batteries. Electrochim. Acta 49, 1057-1061 (2004).

58. Mohamedi, M. et al. Electrochemical investigation of $\mathrm{LiNi}_{0.5} \mathrm{Mn}_{1.5} \mathrm{O}_{4}$ thin film intercalation electrodes. Electrochim. Acta 48, 79-84 (2002).

59. Macdonald, D. D. Reflections on the history of electrochemical impedance spectroscopy. Electrochim. Acta 51, 1376-1388 (2006).

60. Wang, F. et al. A rechargeable aqueous $\mathrm{Zn}^{2+}$-battery with high power density and a long cycle-life. Energy Environ. Sci. 11, 3168-3175 (2018). 
61. Meng, Y. et al. Direct vapor-liquid-solid synthesis of all-inorganic perovskite nanowires for high-performance electronics and optoelectronics. ACS Nano 13, 6060-6070 (2019).

62. Kresse, G. et al. Efficient iterative schemes for ab initio total-energy calculations using a plane-wave basis set. Phys. Rev. B 54, 11169 (1996).

63. Xie, J. et al. Molecular crowding electrolytes for high-voltage aqueous batteries. Nat. Mater. 19, 1006-1011 (2020).

64. $\mathrm{Bi}, \mathrm{H}$. B. et al. A universal approach to aqueous energy storage via ultralowcost electrolyte with super-concentrated sugar as hydrogen-bond-regulated solute. Adv. Mater. 32, 2000074 (2020).

65. Perdew, J. P. et al. Generalized gradient approximation made simple. Phys. Rev. Lett. 77, 3865 (1996).

66. Blochl, P. E. Projector augmented-wave method. Phys. Rev. B Condens Matter 50, 17953-17979 (1994).

67. Grimme, S. et al. A consistent and accurate ab initio parametrization of density functional dispersion correction (DFT-D) for the 94 elements H-Pu. J. Chem. Phys. 132, 154104 (2010).

68. Nosé, S. A unified formulation of the constant temperature molecular dynamics methods. J. Chem. Phys. 81, 511 (1984).

\section{Acknowledgements}

This research was supported by the National Key R\&D Program of China (no. 2019YFA0705104 (C.Z.)). The work was also partially sponsored by GRFs under Project CityU 11305218 (C.Z.), CityU 11212920 (C.Z.), and the Guangdong Innovative and Entrepreneurial Research Team Program (no. 2016ZT06G587 (W.L.)). The authors would like to thank Mr T. F. Hung for HRTEM analysis.

\section{Author contributions}

Yw.Z.: conceptualization, methodology, and writing. Y.L.: methodology. H.L.: methodology. Yb.Z.: methodology. Y.M.: methodology. N.L.: methodology. D.W.: methodology. F.J.: methodology. F.M.: methodology. C.L.: methodology. Y.G.: methodology. X.L.: methodology. Z.H.: methodology. Q.L.: methodology. J.C.H.: methodology. J.F.: methodology. M.S.: methodology. F.C.: methodology, review, and editing. W.Z.: methodology, review \& editing. W.L.: methodology, review, and editing. C.Z.: conceptualization, funding acquisition, writing - review and editing.

\section{Competing interests}

The authors declare no competing interests.

\section{Additional information}

Supplementary information The online version contains supplementary material available at https://doi.org/10.1038/s41467-022-28380-y.

Correspondence and requests for materials should be addressed to Wenguang Zhu, Weishu Liu or Chunyi Zhi.

Peer review information Nature Communications thanks the anonymous, reviewer(s) for their contribution to the peer review of this work. Peer reviewer reports are available.

Reprints and permission information is available at http://www.nature.com/reprints

Publisher's note Springer Nature remains neutral with regard to jurisdictional claims in published maps and institutional affiliations.

cc (i) Open Access This article is licensed under a Creative Commons Attribution 4.0 International License, which permits use, sharing, adaptation, distribution and reproduction in any medium or format, as long as you give appropriate credit to the original author(s) and the source, provide a link to the Creative Commons license, and indicate if changes were made. The images or other third party material in this article are included in the article's Creative Commons license, unless indicated otherwise in a credit line to the material. If material is not included in the article's Creative Commons license and your intended use is not permitted by statutory regulation or exceeds the permitted use, you will need to obtain permission directly from the copyright holder. To view a copy of this license, visit http://creativecommons.org/ licenses/by/4.0/.

(C) The Author(s) 2022 